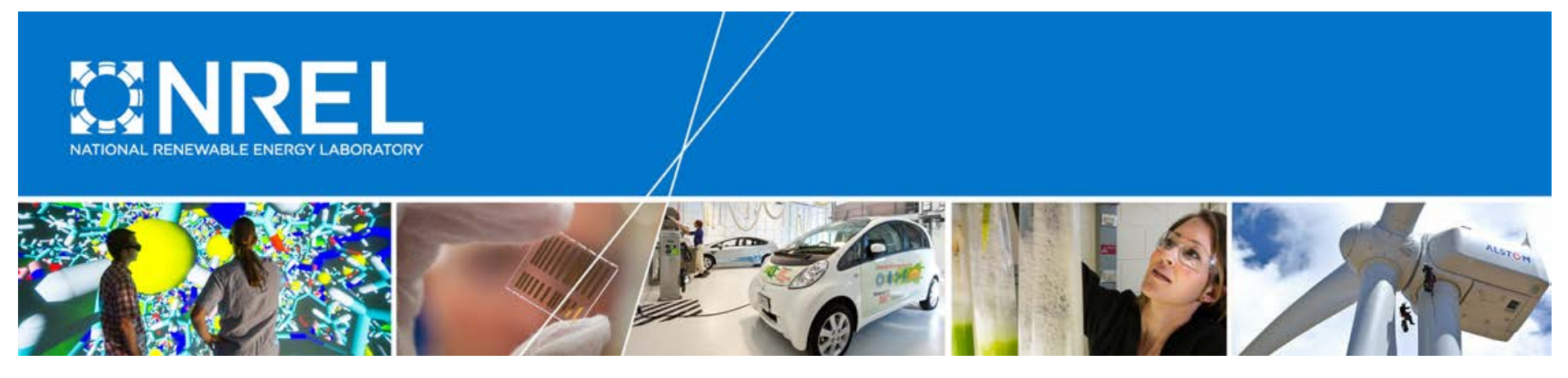

\title{
Enabling the SMART Wind Power Plant of the Future Through Science-Based Innovation
}

Katherine Dykes, Maureen Hand, Tyler Stehly, Paul Veers, Mike Robinson, and Eric Lantz National Renewable Energy Laboratory

Richard Tusing

Allegheny Science and Technology

NREL is a national laboratory of the U.S. Department of Energy Office of Energy Efficiency \& Renewable Energy Operated by the Alliance for Sustainable Energy, LLC

This report is available at no cost from the National Renewable Energy Laboratory (NREL) at www.nrel.gov/publications.

Technical Report

NREL/TP-5000-68123

August 2017

Contract No. DE-AC36-08GO28308 


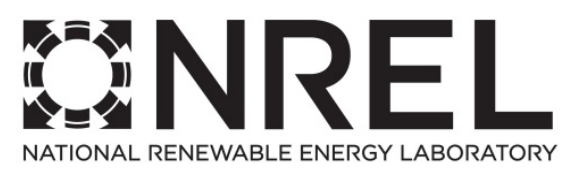

\section{Enabling the SMART Wind Power Plant of the Future Through Science-Based Innovation}

Katherine Dykes, Maureen Hand, Tyler Stehly, Paul Veers, Mike Robinson, and Eric Lantz National Renewable Energy Laboratory

Richard Tusing Allegheny Science and Technology

NREL report prepared for the U.S. Department of Energy Wind Energy Technologies Office

Prepared under Task No. WE15.CA03

NREL is a national laboratory of the U.S. Department of Energy Office of Energy Efficiency \& Renewable Energy Operated by the Alliance for Sustainable Energy, LLC

This report is available at no cost from the National Renewable Energy Laboratory (NREL) at www.nrel.gov/publications.

National Renewable Energy Laboratory 15013 Denver West Parkway Golden, CO 80401 303-275-3000 • www.nrel.gov
Technical Report

NREL/TP-5000-68123

August 2017

Contract No. DE-AC36-08G028308 


\title{
NOTICE
}

This report was prepared as an account of work sponsored by an agency of the United States government. Neither the United States government nor any agency thereof, nor any of their employees, makes any warranty, express or implied, or assumes any legal liability or responsibility for the accuracy, completeness, or usefulness of any information, apparatus, product, or process disclosed, or represents that its use would not infringe privately owned rights. Reference herein to any specific commercial product, process, or service by trade name, trademark, manufacturer, or otherwise does not necessarily constitute or imply its endorsement, recommendation, or favoring by the United States government or any agency thereof. The views and opinions of authors expressed herein do not necessarily state or reflect those of the United States government or any agency thereof.

This report is available at no cost from the National Renewable Energy Laboratory (NREL) at www.nrel.gov/publications.

Available electronically at SciTech Connect http:/www.osti.gov/scitech

Available for a processing fee to U.S. Department of Energy and its contractors, in paper, from:

\author{
U.S. Department of Energy \\ Office of Scientific and Technical Information \\ P.O. Box 62 \\ Oak Ridge, TN 37831-0062 \\ OSTI http://www.osti.gov \\ Phone: 865.576.8401 \\ Fax: 865.576.5728 \\ Email: reports@osti.gov
}

Available for sale to the public, in paper, from:

\author{
U.S. Department of Commerce \\ National Technical Information Service \\ 5301 Shawnee Road \\ Alexandra, VA 22312 \\ NTIS http://www.ntis.gov \\ Phone: 800.553 .6847 or 703.605 .6000 \\ Fax: 703.605.6900 \\ Email: orders@ntis.gov
}




\section{Acknowledgments}

We would like to thank the principal investigators of wind activities within the U.S. Department of Energy (DOE) Wind Energy Technologies Office research portfolio. At the National Renewable Energy Laboratory, this includes Daniel Laird, Patrick Moriarty, Jason Fields, Matthew Churchfield, Andrew Clifton, Julie Lundquist, David Corbus, Walter Musial, Phillip Beiter, Jonathan Keller, Shawn Sheng, and Paul Fleming. At Sandia National Laboratories, this includes David Womble, Brian Naughton, Joshua Paquette, David Maniaci, and Jonathan White. At Pacific Northwest National Laboratory, this includes William Shaw.

This work was supported by DOE under Contract No. DE-AC36-8GO28308 with the National Renewable Energy Laboratory. Funding for the work was provided by the DOE Office of Energy Efficiency and Renewable Energy, Wind Energy Technologies Office. 


\section{Executive Summary}

The potential for wind power in the United States and globally is vast. The U.S. wind resource alone could supply more than 7.5 times the nation's total electricity generation in the year 2016 . The nation has already begun to harness this potential. In 2016, new investments in U.S. wind power capacity were estimated at $\$ 14.5$ billion and wind power supplied more than $5.5 \%$ of U.S. electricity generation. Future generations of technologically advanced wind power are anticipated to provide consumers with wind energy at unsubsidized costs competitive with or lower than other new and existing generation resources.

The advancement of scientific knowledge coupled with technology development and innovation underpins the long-term market potential for wind power in the United States and around the globe. An essential element of future wind technology is a move toward highly optimized and integrated plant design and operations that focus on the design and development of the entire wind plant rather than individual wind turbines. The collection of intelligent and novel technologies that comprise this next-generation technology can be characterized as "System Management of Atmospheric Resource through Technology," or SMART strategies. SMART wind power plants will be designed and operated to achieve enhanced power production, more efficient material use, lower operation and maintenance and servicing costs, lower risks for investors, extended plant life, and an array of grid control and reliability features.

The realization of the SMART wind power plant is projected to result in an unsubsidized cost of energy of $\$ 23 /$ megawatt-hour and below, a reduction of $50 \%$ or more from current cost levels. Under this scenario, wind energy deployments in the United States could increase to more than 200 gigawatts by 2030 and 500 gigawatts by 2050 , supplying respectively $20 \%$ and $47 \%$ of U.S. electricity with wind. Relative to a business-as-usual scenario, this investment in technology research and innovation could support as much as $\$ 150$ billion in cumulative electric sector cost savings from 2017 to 2050 .

The U.S. Department of Energy's (DOE's) Wind Energy Technologies Office Atmosphere to Electrons (A2e) applied research program has been initiated to advance the fundamental science that is necessary to drive innovation and the realization of the SMART wind power plant of the future. The multiple atmospheric and physical processes involved, coupled with the multiple length and time scales, make the wind modeling problem a computational "grand challenge," requiring the world's largest computers and advanced computationally efficient algorithms to resolve. The A2e activities are a unique collection of scientific efforts that leverage governmental subject matter and computational science expertise, access to interagency data, and high-performance computing facilities to significantly advance the understanding of the underlying physics of wind power and transform industry wind turbine and plant designs. This report describes the scientific challenges facing wind today and the recent scientific advancements that position the research community to tackle those challenges, as well as the new DOE applied research program A2e that takes an integrated approach to addressing those challenges. It also ties these resulting scientific accomplishments to future technological innovation and quantifies the impact of that collection of innovations on the cost of energy from wind power in 2030. 


\section{Scientific Challenges in Wind Energy and the A2e Applied Research Program}

The core science needed to advance the next generation of wind energy technology is linked to researchers' fundamental understanding of wind power plant physics, from the source of wind flow in the atmosphere to small scales of flow through the plant, including how the wind plant interacts with that flow. Though the wind industry and wind energy technology have advanced dramatically in recent decades, uncertainty in the science around wind plant physics threatens to limit future innovation in wind turbine and power plant technology that will make wind energy cost competitive nationwide. The ability to truly understand, control, and predict the performance of the future wind plant relies on understanding and tying together a range of physical phenomena from regional weather systems to the wind flow that passes over individual wind turbine rotor blades.

Recent advances in supercomputing technology, as well as sophisticated atmospheric measurement capabilities and large sets of data from turbine-based systems, provide the ability to study the wind and wind/turbine interactions as never before. The A2e applied research program leverages these advances into an integrated effort so that, for the first time, researchers will be able to accurately model the behavior of wind flow into and through a wind plant at a level of resolution that illustrates the full flow physics. Scientists will apply supercomputing to highfidelity physics models (HFMs) of complex flows and will use "Big Data" along with data science to manage extensive measurements that provide formal validation of supercomputing models.

The A2e applied research program is a joint public/private partnership implemented as multiple collaborative projects involving DOE, the national laboratories, and industry and academic stakeholders. DOE, with significant private sector input, is identifying the underlying physical science challenges limiting innovation and is engaging systematically in wind energy science research to resolve those challenges. The structure of the A2e initiative as well as the explicit linkages to industry were created with the specific intent to rectify private sector underinvestment in broad-based scientific advancement while simultaneously using new scientific knowledge and computational capabilities to support private sector technology innovation and commercialization.

The coordinated A2e applied research program includes several major research focus areas:

- Performance, risk, uncertainty, and financing: focuses on increased understanding and confidence to lower the actual and perceived risks and uncertainties of wind power plants

- High-fidelity modeling, verification, and validation: uses HFM, supercomputing, and data science methods in concert to understand and accurately model fundamental physics on appropriate temporal and spatial scales that will in turn improve understanding of complex flow through the wind plant and to provide credible assessment of computational accuracy and uncertainty within a verification and validation paradigm

- Wind power plant controls: develops the technical capabilities to enable integrated realtime plant sensing and control 
- Integrated system design and analysis: enables full life cycle, site-specific, cost-of-energy wind power plant optimization

- Wind power plant reliability: seeks to increase inherent reliability and reduce uncertainty around component and system failures.

Through the integration of these efforts, A2e will use supercomputing capabilities and validated HFMs to provide fully resolved wind plant flow interactions. In doing so, A2e will advance wind energy science by quantifying, reducing, and potentially eliminating uncertainty around the wind resource and how it flows through the plants, as well as uncertainty related to the turbine and plant response to that flow. These knowledge gains will be used to inform design standards and processes, enhance industry design capabilities, and demonstrate where innovation has significant potential for cost reduction, performance enhancement, and grid service.

Industry is an active participant in the A2e applied research program advising the program on strategic direction and informing the research focus areas on the importance of various sources of uncertainty and scientific knowledge gaps. Industry will also collaborate directly on experimental campaigns, utilizing results and capabilities developed in the research focus areas to develop technology innovations and to improve wind turbine and power plant design, control, and operation. Industry will lead the commercialization of novel technology developed with A2e research efforts.

\section{Realizing the SMART Wind Power Plant of the Future}

Projected A2e advances in fundamental, applied, and computational science will allow industry to redesign and optimize wind power components, plants, and operational strategies around the objectives of substantially lowered costs and enhanced grid control and reliability support functions as part of the SMART wind power plant of the future. These wind turbine, plant, and grid integration innovations will allow SMART wind power plants to respond to the atmosphere as an efficient, integrated system that supports the broader power system. Key innovations enabled through this research include:

- High-fidelity wind power plant energy production estimation: leverages sophisticated HFM capabilities for the wind power plant to optimize site-specific wind plant design with improved accuracy in performance predictions

- Integrated wind power plant design, control, and operational strategies: leverage realtime monitoring of the wind resource as it enters and passes through the wind power plant and apply advanced understanding of the flow to the development of system-level control strategies that optimize performance and actively manage and direct the entire flow moving through the plant

- Innovative wind turbine machine design and technology: develops innovative rotor and drivetrain technology as well as further scaling of wind turbine technologies enabled by accurate characterization of the wind turbine operating environment at higher heights

- Controllable, dispatchable, and predictable grid support services: reflect the important role of wind plants in the future electric grid system such that wind power plants provide 
energy with well-quantified uncertainty and adapt and respond to grid operational requirements for both stability and operational planning.

While the research community and industry are already working toward innovations in several of these areas, the SMART wind power plant of the future represents the culmination of a decade of advances in innovations that will build on A2e science. The resulting SMART wind power plant of the future contains turbines of various sizes each optimized to site-specific plant conditions with advanced technology and significant scaling. There is extensive real-time data collected from both the turbines and meteorological measurement equipment that are integrated at the control operations center for highly accurate forecasting of the plant energy production and full wind plant control that balances maximization of energy production with plant reliability and grid services. The real-time controls implemented within the plant leverage highly accurate information about the wind resource flow into and through the plant so that it can be directed dynamically according to plant operation objectives that allow for higher reliability and longer plant lifetime. Through this combination of innovations, the SMART wind power plant of 2030 reduces the current cost of energy by $50 \%$ and beyond.

\section{The 2030 Cost of Wind Energy}

Enabled by A2e wind energy science, industry is expected to innovate and commercialize new technologies and evolve wind power plants to provide cost-effective wind power nationwide. More specifically, applying SMART wind power plant innovations at a site with an 8-meter-persecond mean wind speed resource is estimated to result in an unsubsidized range of projected 2030 wind cost of energy of \$19-\$32/megawatt-hour, with an expected unsubsidized cost of energy of $\$ 23 /$ megawatt-hour, a reduction of $50 \%$ or more from current cost levels. This accelerated research and development pathway incorporates levelized cost of energy reductions resulting from incremental improvements to technology through scaling and learning as well as innovation enabled by A2e scientific advances. Specific cost-reduction impacts are anticipated to include:

- Capital expenditures reduction of $21 \%$ through scaling the size of the turbine and a range of other innovations in turbine design and manufacturing

- Annual energy production increase of $22 \%$ through scaling, innovation in turbine design, and optimal wind plant design and control

- Operational expenditures reduction of $25 \%$ through advancing modeling, sensing, data analysis, and assimilation

- Financing costs reduction of 5\% by lowering long-term production risk through advanced modeling, sensing, data analysis, and assimilation

- An increase in wind power plant lifetime to reduce cost of capital by $26 \%$ through extension of amortization periods. 
The significant efforts and success of A2e over the next several years with a strong interaction and exchange of information with public and private sector project partners is expected to enable and support innovation over the next decade. In turn, the combination of DOE and industry efforts will realize the accelerated research and development pathway for cost-competitive wind energy nationwide.

\section{Conclusions}

Fundamental scientific advances are needed to drive broad-based wind power competitiveness and support a new era of abundant low-cost energy. A2e wind energy science research is designed to enable new wind plant innovations that could lower the cost of wind energy by $50 \%$, relative to current technology; facilitate wind power deployment nationwide; and potentially contribute to U.S. technology exports. Achieving this reduction requires SMART wind power plant technologies that are designed at the plant level to account for and take advantage of the full range of physical processes impacting wind plant performance and adopt new strategies to actively control and convert the wind energy resource into electricity that seamlessly integrates into the grid. The resources available within the DOE program and national laboratory complex - including subject matter expertise, computational science capabilities, and highperformance computing facilities - are uniquely positioned to resolve these scientific challenges. Through active collaboration with industry, DOE will use the A2e program to provide a deeper understanding in the applied science for wind energy and enable industry to advance technology for the SMART wind power plant of the future. 


\section{Table of Contents}

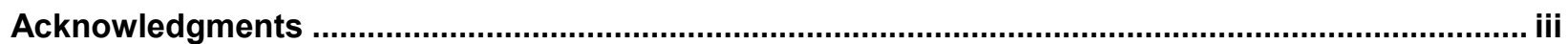

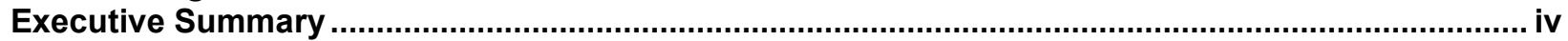

I. Scientific Challenges in Wind Energy and the A2e Applied Research Program........................ V

II. Realizing the SMART Wind Power Plant of the Future ........................................................... vi

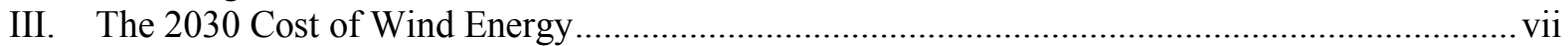

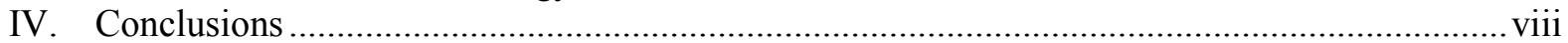

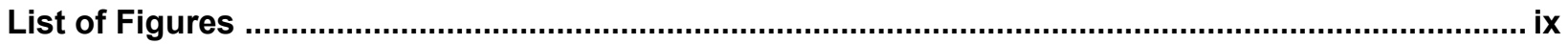

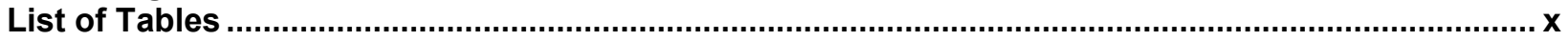

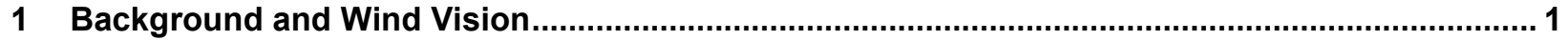

2 Scientific Challenges in Wind Energy and the A2e Applied Research Program .......................... 3

3 Enabling the SMART Wind Power Plant Through Advances in Wind Energy Science................ 9

3.1 From A2e Applied Research to SMART Wind Power Plant Cost of Energy ............................ 11

3.2 High-Fidelity Wind Power Plant Energy Production Estimation............................................. 12

3.3 Integrated Wind Power Plant Design, Control, and Operational Strategies.............................. 13

3.4 Innovative Wind Turbine Machine Design and Technology ................................................... 14

3.5 Controllable, Dispatchable, and Predictable Grid Support Services ........................................ 16

3.6 Summary of LCOE Impacts from Science-Enabled Innovations.............................................. 18

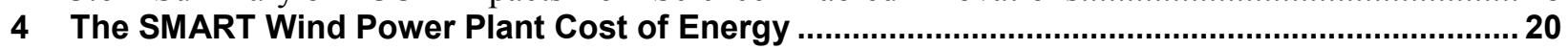

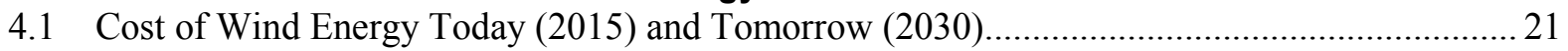

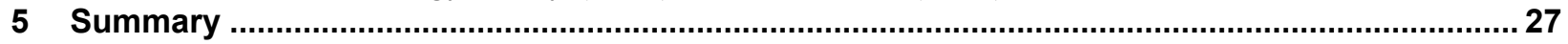

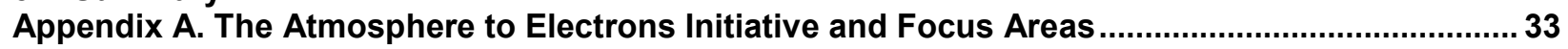

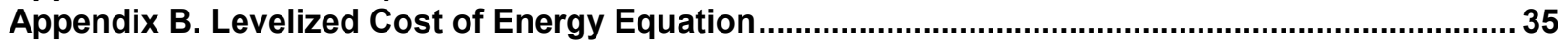

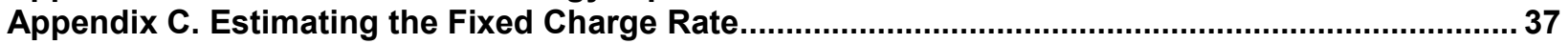

Appendix D. Cost of Energy Estimate Details............................................................................ 38

Appendix E. Harnessing Immense Offshore and Distributed Wind Potential with Advanced

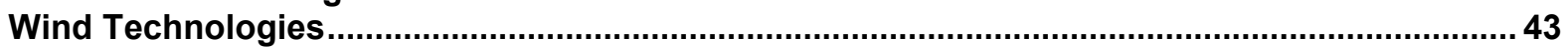

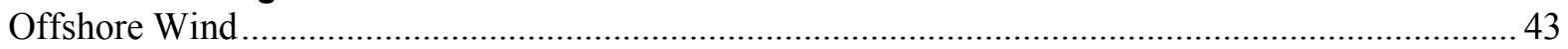

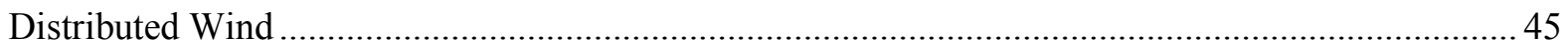

\section{List of Figures}

Figure 1. The complexity of the entire physical system of wind flow from large regional scales to small-scale intraturbine flows. Illustration by Josh Bauer and Al Hicks, National Renewable Energy Laboratory (NREL) ..................................................................... 3

Figure 2. Visualization of a simulated wind turbine wake as sampled by a motorized lidar. Image courtesy of Matthew Churchfield, NREL ..................................................................... 5

Figure 3. Organization of A2e focus areas and dependencies between them ................................... 7

Figure 4. The wind plant of today (top) compared to the SMART wind power plant of tomorrow (bottom). Illustration by Josh Bauer, NREL .................................................................

Figure 5. The relationship between $A 2 e$ research, system innovation, and cost of energy. The collective activities of A2e when integrated together will advance wind energy science to enable a spectrum of wind energy innovations (broadly categorized as shown in the graphic). In turn, the innovations, when combined together, will have large impacts on cost of energy parameters from improved energy production to significant reductions in all costs. Illustration by Josh Bauer, NREL

Figure 6. U.S. land-based wind projects installed in 2015. IIIustration from American Wind Energy Association Projects Database, NREL

Figure 7. Projected wind power plant costs for the SMART wind power plant using an accelerated R\&D pathway relative to future natural gas prices

Figure 8. Projected costs for the SMART wind power plant at a range of different wind resource sites using the accelerated R\&D pathway relative to future natural gas prices.......... 24 
Figure 9. Pathway to $50 \%$ LCOE reduction in 2030 by LCOE parameter

Figure E-1. Recent strike prices for offshore wind plants in European waters. Data derived from Garlick, Auckland, Zhang (2017).

Figure E-2. Six different offshore wind substructure types. Offshore wind systems are enhancing foundation concepts to reduce the significant challenge of installation in deep water at a low cost. Illustration by Josh Bauer, National Renewable Energy Laboratory.

\section{List of Tables}

Table 1. High-Fidelity Wind Power Plant Energy Production Estimation Interdependencies of Technology Innovation, Scientific Advancements, and LCOE Impact Potential

Table 2. Integrated Wind Power Plant Design, Control, and Operational Strategy Interdependencies of Technology Innovations, Scientific Advancements, and Impact Potential.

Table 3. Innovative Wind Turbine Machine Design and Technology Interdependencies of Technology Innovations, Scientific Advancements, and Impact Potential.

Table 4. Controllable, Dispatchable, and Predictable Grid Support Service Interdependencies of Technology Innovations, Scientific Advancements, and Impact Potential ............................ 17

Table B-1. Summary of Variables in LCOE Calculation ................................................................ 35

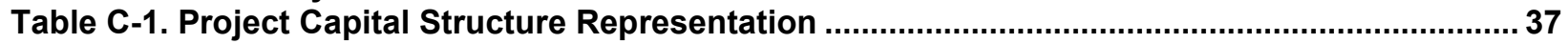

Table D-1. 2015 Land-Based Wind Plant Characteristics .............................................................. 39

Table D-2. Comparison of the 2015 Baseline Wind Power Plant with the Reference Project

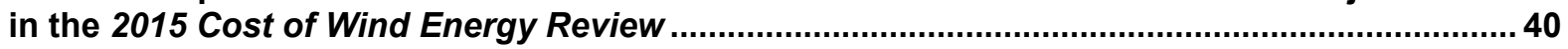

Table D-3. Projected 2030 Land-Based Wind Plant Characteristics for the Accelerated R\&D Pathway

Table D-4. Projected 2030 Land-Based Wind Power Plant Characteristics for the Lower LCOE Range.

Table D-5. Projected 2030 Land-Based Wind Power Plant Characteristics for the Higher LCOE Range. 


\section{Background and Wind Vision}

The Wind Vision study published by the U.S. Department of Energy (DOE) in 2015 explored how wind power could meet $20 \%$ of the U.S. electricity demands by 2030 and $35 \%$ by 2050 (DOE 2015). Achieving the Wind Vision study scenario is expected to have both economic and societal benefits for the nation. Key benefits expected by 2050 include a $2 \%$ savings in annual national electricity costs, over 600,000 direct (e.g., manufacturing, construction, installation, and operations) and induced jobs, cumulative consumer cost savings of $\$ 280$ billion from reduced natural gas prices outside of the electricity sector, and $23 \%$ reduction in water consumed by the electric sector. In addition, this scenario provides over $\$ 3$ billion/year (yr) in wind-derived property tax payments and more than $\$ 1$ billion/yr in land-lease revenues. Substantial reductions in electricity sector emissions are also anticipated, resulting in a public health savings of $\$ 108$ billion because of reductions in sulfur oxides, nitrogen oxides, and fine particulate matter.

As of the end of 2016, the United States had an installed wind capacity of 82 gigawatts (GW), enough to provide more than $5.5 \%$ of the nation's electricity demand and power 24 million homes (American Wind Energy Association 2016). To move from 5.5\% to 20\% and eventually $35 \%$ wind generation, wind energy must improve its current cost-competitive position with other generation sources. In the best wind resource areas, wind energy generation has already reached cost parity with traditional power sources. As this report shows, through science and innovation, an additional reduction in the cost of wind energy of $50 \%$ from current costs is achievable.

Although research and development $(\mathrm{R} \& \mathrm{D})$ is working toward increasing cost competitiveness, today's wind energy technologies reflect a historical turbine-centric development R\&D pathway, with each machine operating in isolation to maximize individual turbine performance and neglecting the substantive opportunities for enhanced performance, operating as an integrated wind power plant system. The larger electric grid system simply accepts the aggregated plant power output from all interconnected turbines as an energy source that reduces the fuel consumption needed by conventional generation to meet electricity demand. However, the grid also needs consistent electrical frequency and voltage (and other) ancillary services that traditionally were controlled at the central power plants. Depending on the grid size, existing assets, and proportion of wind energy on the grid (wind penetration level), additional ancillary services may be necessary to balance the wind resource variability.

To advance the deployment of wind energy in a manner consistent with the Wind Vision study scenario, DOE's Wind Energy Technologies Office has invested in the Atmosphere to Electrons (A2e) research initiative. This research program focuses on advancing wind energy science to enable industry-led component and plant-level innovations that reduce the cost of wind energy to achieve unsubsidized cost competitiveness with gas-fired electricity fuel costs. This paper summarizes the R\&D pathway: from wind energy science challenges to the A2e applied research program to enabling innovation, including the realization of the "System Management of Atmospheric Resource through Technology" (SMART) wind power plant, and finally to achieving cost-competitive wind energy nationwide. Section 2 provides an overview of the science challenges facing the wind industry and how they will be addressed by the A2e applied research program. Section 3 provides a detailed description of how specific advancements in science will enable the innovation necessary to realize the SMART wind power plant. Section 4 provides an overview of the SMART wind power plant and the R\&D pathway it will use to 
reduce wind cost of energy by $50 \%$ of current costs. Finally, Section 5 provides a summary of the potential impacts of scientific advancements expected from A2e as well as the overall impact on wind power plant cost of energy. 


\section{Scientific Challenges in Wind Energy and the A2e Applied Research Program}

A comprehensive understanding of wind energy science can help the wind industry realize lowcost, large-scale, and grid-compatible wind deployment. Understanding atmospheric behavior, including how large-scale and regional weather systems drive the wind flow to, down, into, and through the wind power plant, can help the wind industry and research community quantify, reduce, and eliminate uncertainties (Figure 1).

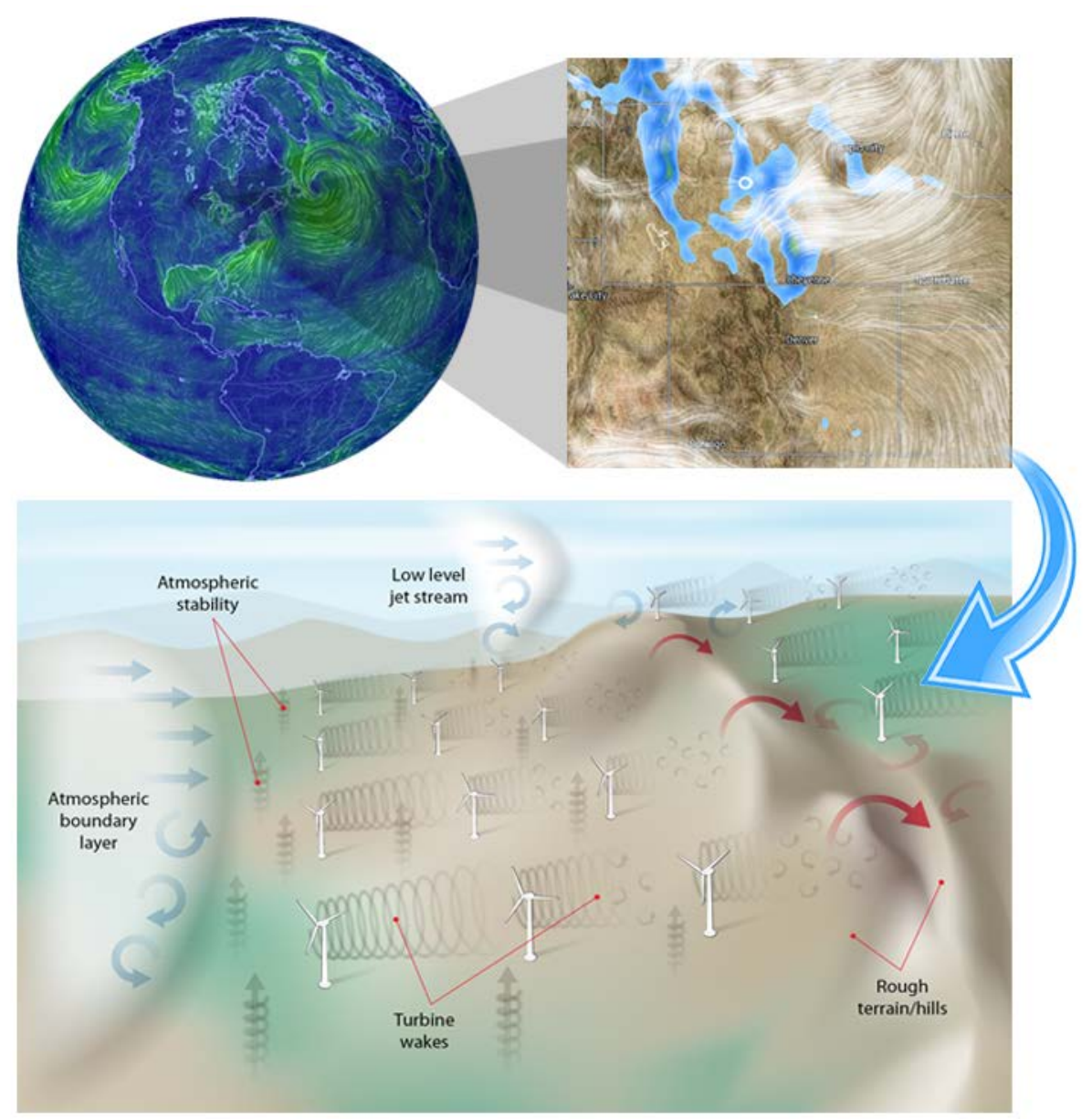

Figure 1. The complexity of the entire physical system of wind flow from large regional scales to small-scale intraturbine flows. Illustration by Josh Bauer and Al Hicks, National Renewable Energy Laboratory (NREL)

The wind inflow is determined by weather-driven phenomena at physical length scales of multiple kilometers. At the same time, the energy produced by the wind power plant depends on the flow within the plant that is affected by the collective behavior of the turbines therein. Furthermore, specific energy produced from an individual wind turbine and the forces on its structure depend on local wind flow structures at sizes ranging from meters (blade and rotor scale) to millimeters near the wind turbine blade surface (the blade boundary layer scale). Several recent reports detail the scientific challenges within and across these scales (Sprague et al. 2015; Womble et al. 2015; Maniaci and Naughton forthcoming; Haupt et al. 2015, 2017). The uncertainty and lack of ability to model and predict these flows impose limitations on current 
wind turbine design and innovation because actual conditions often differ from what can be predicted (Sprague et al. 2015; Damiani forthcoming). Furthermore, these uncertainties impact the ability for industry to develop more integrated and optimized approaches to wind power plant design and operation (Damiani forthcoming; Clifton, Smith, and Fields 2016; Boersma et al. 2017). For offshore wind power plants, the uncertainties are compounded by the scientific questions around oceanographic conditions including waves, currents, tides, and more (Gilman et al. 2016). Significant innovation in wind power plant technologies will require the ability to truly understand, control, and predict the performance of a wind power plant and each of the plant's wind turbines, which relies on tying together this range of physical phenomena from the regional weather system to the blade boundary layer.

The multiple atmospheric and physical processes involved, coupled with the multiple-length scales, make the wind modeling problem a computational "grand challenge," requiring the world's largest computers and advanced computationally efficient algorithms to resolve. ${ }^{1}$ Although scientists have made strides in understanding the flow of wind at each physical scale of interest, there is still significant uncertainty in the physics at each scale and, to an even greater extent, the interactions of flow between scales. To illustrate the complexity of flow between turbines within a plant, Figure 2 demonstrates state-of-the-art simulation and measurement of the wind turbine wake (the flow behind a turbine after it extracts energy from the inflow). Wind energy scientists are now able to measure this wake flow behind a turbine in detail and compare the data to model predictions. Accurately modeling wake phenomena will facilitate new strategies for active wake modification and control by manipulating the turbine rotor, blade pitch, and yaw systems (Boersma et al. 2017). Accurately controlling wind turbine wakes will enable the industry to improve wind energy production, enhance the accuracy of energy production estimates, improve reliability of the plant and extend its lifetime, and even design better-performing and more cost-effective wind turbines and power plants in the future (Damiani forthcoming; Clifton et al. 2016).

\footnotetext{
${ }^{1}$ The Advanced Scientific Computing Advisory Committee, a review board for DOE's Office of Science charged with overseeing high-performance computing initiatives in energy, deemed resolving wind power plant performance as a computational "grand challenge."
} 


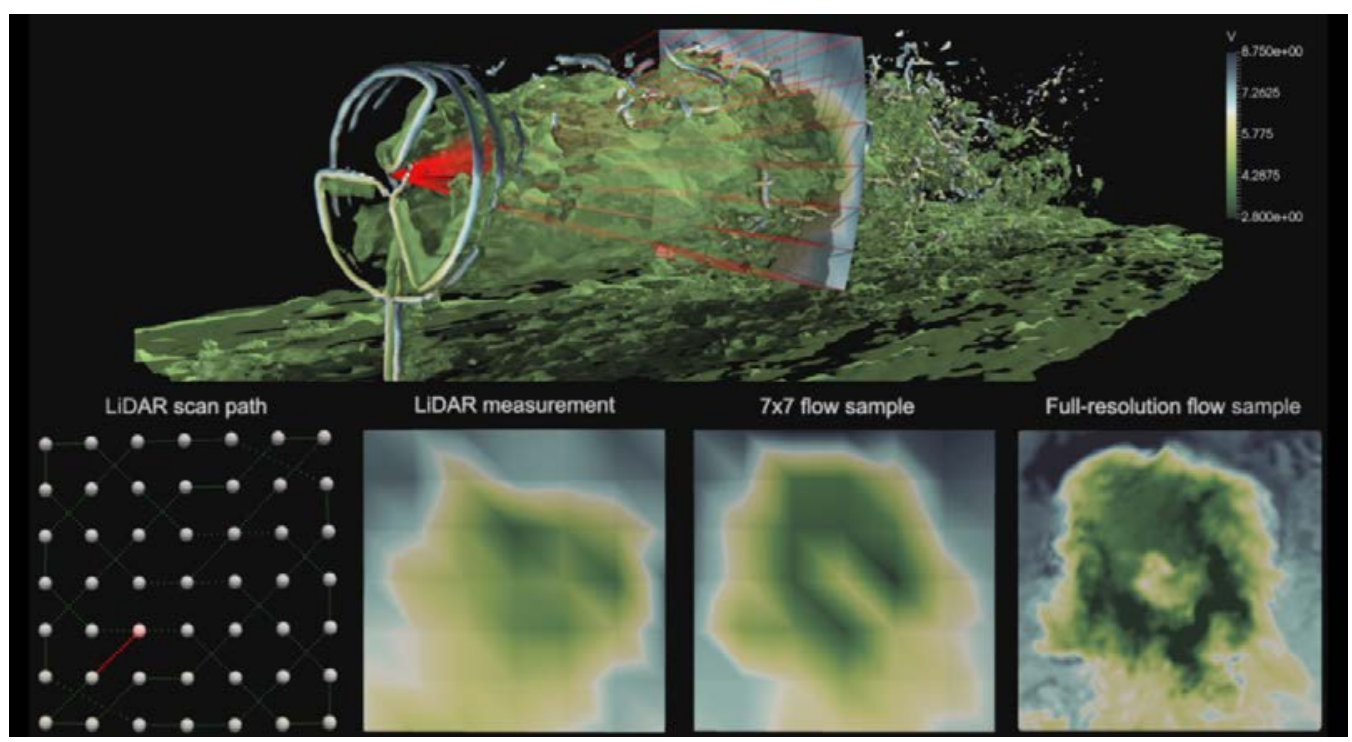

Figure 2. Visualization of a simulated wind turbine wake as sampled by a motorized lidar. Image courtesy of Matthew Churchfield, NREL

Note: The measurement technology still has limitations in how accurately it can represent the flow field because it uses averaging in both time and space. The middle images at the bottom of Figure 2 demonstrate the lower fidelity of the measurement of the wake compared to the full resolution on the lower right that shows more detail. The comparison provides insight into the modeling needed to develop advanced technology to control this flow.

The advancement in understanding the flow associated with wind plants depends on high-fidelity modeling (HFM) of the integrated physics of the atmosphere and wind power plant. The complexity of these models requires the state-of-the-art capability known as supercomputing. Just a decade ago, it was not possible to pursue fundamental science questions around full wind plant flow with the state of supercomputing resources at the time. The current state of supercomputing with physics-based simulation software (physics-based codes) is just beginning to tackle this level of computing challenge (Sprague et al. 2015; Womble et al. 2015; Haupt et al. 2015, 2017).

However, the capability to simulate this type of complex phenomena is of limited use to industry without comprehensive validation of the HFM physics-based computer programs and codes. Validation of the codes requires high-resolution experiments to ensure that the modeling uncertainty is well quantified. In addition, these models must be extensively verified and validated using high-resolution data collected through large-scale measurement campaigns (Hills et al. 2015). Recent advancements in meteorological sensing and measurement equipment (Peña et al. 2015; Lundquist et al. forthcoming) along with "Big Data" allow scientists to quantify wind power plant flow with resolution and accuracy that was not conceivable just a decade earlier.

Through integration of all of these capabilities around supercomputing and high-fidelity modeling, meteorological sensing and measurement equipment, and "Big Data" analysis and assimilation - conducted within a well-defined verification and validation governing framework - researchers will be able to address key wind energy science challenges. The A2e applied research program is designed to directly address the integration of activities, as described above, to advance wind energy science and enable significant innovation in wind technology in the decades to come. 


\subsection{The A2e Applied Research Program}

The A2e research program tackles the science challenges around wind power plant physics by combining all of the above-mentioned capabilities and using them in a set of focused and integrated research activities (see Appendix A for details). The A2e applied research program targets atmospheric science and HFM with large-scale verification and validation campaigns, advanced wind power plant controls, wind power plant reliability, and integrated system design and analysis - all prioritized under the auspices of a formalized wind power plant performance and financial risk assessment methodology. ${ }^{2}$ In turn, advances in each of these areas enable the private sector to create and commercialize novel innovations in wind turbine and power plant technology to achieve substantial cost of energy reductions.

The A2e applied research program is a joint public/private partnership implemented as multiple collaborative projects involving DOE, the national laboratories, and industry and academic stakeholders. DOE, with significant private sector input, is identifying the underlying physical science that is limiting innovation and is engaging systematically in wind energy science research to resolve those challenges.

DOE has the ability to address wind energy science challenges by leveraging laboratory domain expertise in atmospheric science, complex flow, and wind energy technologies. In addition, DOE has world-renowned computing resources and capabilities in computational and data sciences and leadership in the development and implementation of major experimental measurement campaigns. With this combination of expertise and resources, DOE is uniquely positioned to verify and validate the next generation of physics-based models needed for enabling wind energy innovation for future wind power plants. The structure of the A2e initiative as well as the explicit linkages to industry were created with the specific intent of rectifying private sector underinvestment or "market failure" in broad-based scientific advancement while simultaneously using new scientific knowledge and computational capabilities to support private sector technology innovation and commercialization.

Major research efforts of the A2e initiative (see Appendix A for program summary) include:

- Performance, risk, uncertainty, and financing (PRUF) for risk assessment: focuses on understanding and lowering the actual and perceived risks and uncertainties associated with developing, investing in, owning, and operating wind power plants

- High-fidelity modeling, verification, and validation: uses high-performance, parallel computers to understand and accurately model fundamental physics on appropriate temporal and spatial scales to predict complex, rapidly changing inflow to the wind plant, complex flow within the plant, and individual turbine and wind plant responses (as a whole) to the flows, as well as provides credible assessment of computational accuracy and uncertainty within a verification and validation paradigm

\footnotetext{
${ }^{2}$ This paper focuses on the A2e portion of the DOE wind research program. The authors acknowledge the importance of additional research areas related to deployment and other factors that are necessary to realize the Wind Vision, as detailed in the Wind Vision Roadmap. For a detailed overview of the A2e program, visit https://a2e.energy.gov/.
} 
- Wind power plant controls: develops the technical capabilities, methods, and approaches to enable advanced wind power plant control design to optimize wind power plants for both land-based and offshore applications

- Integrated system design and analysis (ISDA): enables full life cycle, site-specific, costof-energy wind power plant optimization by providing a comprehensive analysis capability for land-based and offshore wind plants; coordinating development of open-source, baseline analysis modules; developing and disseminating methods to accurately generate wind power plant design criteria; and incorporating a new wind plant optimization approach into international standards

- Wind power plant reliability: seeks to deliver reliable, lower-cost electricity by increasing inherent reliability and reducing remaining useful life uncertainty, as well as addressing fundamental industrywide technology barriers and knowledge gaps that impede progress.

The sequence of moving from open research questions to demonstrating potential of new innovations to improve wind power plant performance and reduce costs involves each of the above-mentioned research areas. PRUF activities directly engage with the wind industry to identify the sources of uncertainty that most affect current wind plant design and financing (Clifton, Smith, and Fields 2016). These activities inform research efforts around high-fidelity modeling, verification, and validation, in which more detailed analysis is performed to identify the uncertainty around specific physical phenomena in affecting wind turbine and power plant performance (Sprague et al. 2015; Maniaci and Naughton forthcoming). Through execution of integrated HFM and experimental campaigns for verification and validation, A2e will then resolve uncertainties that affect wind turbine and power plant performance at different scales from the mesoscale (large-scale atmospheric flows) to the microscale (within the plant). A2e has specific research activities either already underway or planned at and across each scale (Haupt et al. 2015, 2017; Maniaci et al. forthcoming; Schreck forthcoming).

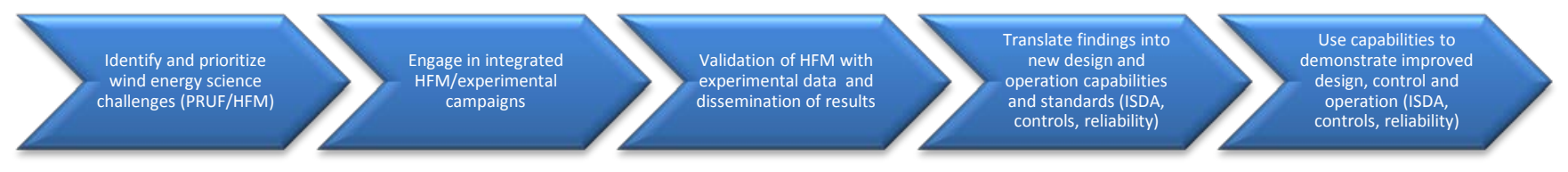

Figure 3. Organization of $A 2 e$ focus areas and dependencies between them

Figure 3 shows how the A2e applied research program areas are organized. Collectively and through time, A2e is advancing wind energy science by quantifying, reducing, and/or eliminating uncertainty around the wind resource and how it flows through the power plants as well as uncertainty related to the turbine and plant response to that flow. The advances in wind energy science gained by HFM, verification, and validation efforts can be used to support wind turbine and plant technology innovation in multiple ways through direct use of the findings or adaptation of the capabilities for use by industry (Jonkman forthcoming). Wind power plant controls and integrated system design and analysis will use one or more of the previously mentioned techniques to leverage the findings from HFM and the verification and validation campaigns to 
create and/or analyze low technology readiness level ${ }^{3}$ innovations in wind turbine and plant technology. Finally, wind power plant reliability will leverage the results across all the other focus areas in collaboration with industry to identify root causes for component failures and tie them back to the overarching wind power plant physics. Through this, A2e will be able to demonstrate the potential for innovations in wind turbine and plant design and operation that will allow for co-optimization of plant performance with reliability and cost. ${ }^{4}$

Industry is engaged in each of the activities, including advising the program on strategic direction, informing the research focus areas on the importance of various sources of uncertainty and scientific knowledge gaps, collaborating directly on experimental campaigns that support verification and validation efforts, utilizing results and capabilities developed in the research focus areas to develop technology innovations and to improve wind turbine and power plant design control and operation, and commercializing innovations developed and demonstrated with A2e research efforts. ${ }^{5}$

The next section ties the research areas of the A2e applied research program to associated advancements in wind energy science and modeling to a collection of industry-commercialized innovations that will realize the SMART wind power plant.

\footnotetext{
${ }^{3}$ Technology readiness levels are used by DOE to categorize various technologies in terms of their maturity and timeline for commercialization. The A2e applied research program is focused on wind energy science research and demonstrating new technology innovations at low technology readiness levels (1-3 from basic research to proof of feasibility). Once technologies have research-sufficient maturity, the industry will develop them to commercial viability.

${ }^{4} \mathrm{~A} 2 \mathrm{e}$ will also support research efforts around grid integration by leveraging the focus areas described earlier to address the design and operation of future wind plants that provide more predictable and reliable energy to the grid. As deployment of wind energy grows, the role of wind power plants in the electric grid system becomes increasingly important. As A2e advances the understanding of wind energy science and demonstrates innovation potential in wind turbine and plant design, control, and operation, the impacts of these innovations will be evaluated from a grid context. The role of the SMART wind power plant in the electric grid is an involved topic that merits its own indepth look. In Section 3, a subsection will be devoted to considering (at a high level) the role of the SMART wind power plant in the electric grid.

${ }^{5}$ An example of an early success of the A2e applied research program is wind power plant controls using wind turbine yaw (the control system that sets the orientation of the wind turbine rotor relative to the incoming wind flow) to steer wind turbine wakes in the farm and increase wind turbine power production. Through the use of highfidelity modeling, the potential of yaw-based wake-steering was demonstrated for a small number of turbines (Fleming et al. 2014; Gebraad et al. 2016). A collaboration between wind power plant controls and integrated system design and analysis then investigated the potential energy production improvement to the entire wind plant (Gebraad et al. 2017). The study demonstrated the opportunity for an increase of a percent or more in annual energy production, which would result in revenue gains for wind plant owner/operators. The potential improvement has gained significant interest from industry and has led to multiple field campaigns involving industry-laboratory collaboration to prove the technology performance (for an example of field-test results in an offshore wind application, see Fleming et al. 2017).
} 


\section{Enabling the SMART Wind Power Plant Through Advances in Wind Energy Science}

The wind industry is cognizant of the substantive paradigm shift necessary to enable future deployment of wind energy. Some aspects of next-generation wind power plants are already emerging in the marketplace. For example, many companies are making significant investments in large computational resources to enable wind power plant digitization, extensive use of sensors, and data collection to create a digital replica of each wind turbine and the entire wind power plant. However, realizing the full potential of wind power plant innovation relies on A2e's continued ability to address several core scientific challenges.

The collective effort of the DOE A2e program and industry will realize a future SMART wind power plant: a collection of intelligent and novel technologies that allow wind power plants and the turbines within them not only to respond to the atmosphere as an efficient, integrated system but also to control the flow itself to maximize power production (Figure 4).

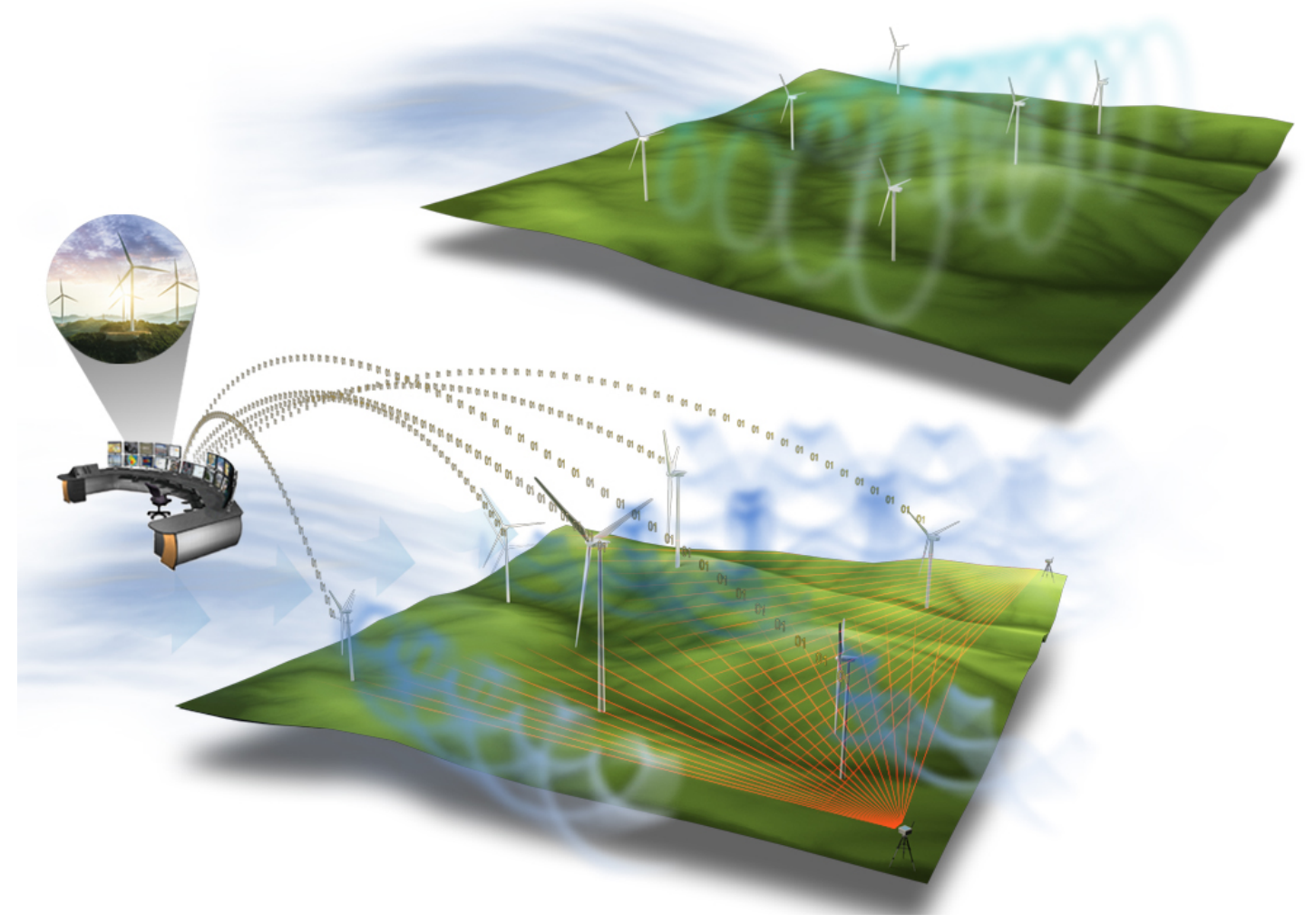

Figure 4. The wind plant of today (top) compared to the SMART wind power plant of tomorrow (bottom). Illustration by Josh Bauer, NREL

In Figure 4, the traditional wind power plant (top) turbines of equal size all face the incoming flow direction, as measured using their own individual sensors, and each tries to maximize its own energy production. There is no plant-level, integrated real-time control or real-time sensing of the wind resource flow into the plant. Data harvested from the wind plant operations are used to support some analysis of trends for performance and reliability, but no large-scale efforts 
around data assimilation and modeling are used to optimize the plant operations. In contrast, the SMART wind power plant of the future contains turbines of various sizes that are each optimized to site-specific plant conditions with advanced technology and significant scaling. There is extensive real-time data collected from both the turbines and meteorological measurement equipment that are integrated at the control operations center for highly accurate forecasting of the plant energy production and full wind plant control that balances maximization of energy production with plant reliability and grid services.

The collection of innovations that define the SMART wind power plant discussed earlier was identified in a series of workshops held with experts from the DOE national laboratory system and reviewed by wind industry experts. Experts were first asked to identify individual innovations and then to aggregate them into groups. The resulting SMART wind power plant can be broken down into groups with specific science-based innovations in each category, including:

\section{- High-fidelity wind power plant energy production estimation:}

○ Apply validated HFM and state-of-the-art sensing equipment to provide energy production estimates with reduced and well-quantified uncertainty

- Integrated wind power plant design, control, and operational strategies:

- Actively monitor the wind resource as it enters and passes through the wind power plant utilizing advanced sensing and data analysis methods to estimate the maximum power extraction potential and loading on all turbines and inform strategies for plant control and operation

- Implement integrated real-time control of all turbines within the wind power plant to actively:

- Entrain (incorporate) additional higher energy atmospheric flow into the wind power plant

- Extract the maximum amount of energy possible flowing through the rotor with adaptive controls on each turbine within the wind plant

- Actively steer lower energy turbine wakes (low energy flow behind the turbine rotors) away from the turbines located downstream to increase plant power production and reduce operating loads

- Execute longer-term operational strategies for increased reliability, reduced costs, and extended operational life

- Design future wind power plants optimized to specific local wind resource conditions and complex terrain

- Innovative wind turbine machine design and technology:

- Advance novel turbine designs that enhance energy capture with rotor designs and drivetrain architectures that optimize and enhance individual turbine performance

- Evolve design standards to tailor the performance characteristics and requirements of each individual turbine within the plant to optimize the overall wind power plant production and cost performance 
- Develop extreme-scale wind turbines with very large rotor diameters and taller towers to capture higher-potential wind energy in the Earth's upper atmosphere

\section{- Controllable, dispatchable, and predictable grid support services:}

- Provide grid services for support of short-term grid stability

- Dispatch generation on demand through plant-level control of wind power plant energy production

○ Provide precise forecast estimates of energy production for short-term grid operation planning including unit commitment and economic dispatch

- Reduce the uncertainty in the overall capacity value of wind power plants to the grid.

Note that the above-mentioned collection of innovations is equally applicable to land-based wind power plants as to offshore wind power plants. For offshore wind applications, additional innovations are likely to occur around the support structure for the machine and plant-level innovations to reduce installation as well as operations and maintenance costs that tend to be very high offshore where access is difficult (see Appendix E for more discussion on offshore wind applications).

\subsection{From A2e Applied Research to SMART Wind Power Plant Cost of Energy}

A metric commonly used to estimate the cost of energy is the levelized cost of energy (LCOE). LCOE reflects the present value of power plant costs divided by the future energy production over the expected lifetime of the wind power plant. LCOE does not necessarily capture all of the costs imposed on the electrical system but provides a consistent basis for measuring and calculating improvements. Wind power plant LCOE relies on four primary parameters (see Appendix B for calculation method):

- Capital expenditures ([CapEx], in \$/kilowatt [kW]). The total upfront investment cost required to achieve commercial operation of a wind power plant including development, transportation, installation, and equipment costs.

- Operational expenditures ([OpEx], in $\$ / \mathrm{kW} / \mathrm{yr})$. The estimated annual operation costs for the life of a wind power plant including fixed expenses, such as property taxes and insurance, as well as variable expenses, such as component replacements and maintenance costs.

- Annual energy production ([AEP], kilowatt-hour/kW/yr). The annual average energy production delivered to the electric grid over the life of the wind power plant.

- Fixed charge rate ([FCR], in percentage). A coefficient that captures the average annual carrying charges including return on invested capital, depreciation, and taxes. Two of the key parameters that impact FCR are the assessed risk associated with a wind energy project and the planned lifetime for the power plant during which financing will take place. These two factors - risk reductions in financing and financed power plant lifetime - are of interest in terms of potential improvement enabled by A2e efforts. 
The innovations that comprise the SMART wind power plant will affect AEP, CapEx, OpEx, and FCR. For each innovation group defined for the SMART wind power plant, the wind energy experts performed a two-sided assessment. On one side, they assessed the causal links between A2e wind energy advancements and the ability to achieve the identified innovations. On the other, they provided a quantified estimate of the potential impact of the group of innovation to wind power plant performance and cost (AEP, CapEx, OpEx, and FCR). Sections 3.2-3.5 describe the innovation areas in detail and demonstrate the dependencies of these advancements on $\mathrm{A} 2 \mathrm{e}$ research.

\subsection{High-Fidelity Wind Power Plant Energy Production Estimation}

Currently, industry standard tools for estimating long-term wind power plant energy production include nontrivial simplifications because of the limited understanding of the links between different atmospheric conditions and wind power plant productivity. In addition, the current understanding of wind turbine wakes and the effect of upstream turbines on downstream turbines is oversimplified and lacks robustness.

An enhanced measurement and modeling capability resulting from A2e focusing on risk, uncertainty assessment, and high-fidelity modeling, verification, and validation will improve predictions of wind power plant performance in two ways. First, the improved capability will directly lead to more accurate calculations of power plant output under well-defined atmospheric conditions whose influence on plant performance is well understood. Second, having a better understanding of how wind power plants perform over the spectrum of realistic atmospheric conditions will enable better design of future power plants and greater accuracy in the estimation of long-term energy production. Table 1 depicts the relationships between innovation in wind power plant energy production, the enabling science required, and the impact to LCOE.

Table 1. High-Fidelity Wind Power Plant Energy Production Estimation Interdependencies of Technology Innovation, Scientific Advancements, and LCOE Impact Potential

\begin{tabular}{|c|c|c|}
\hline $\begin{array}{l}\text { Technology } \\
\text { Innovation }\end{array}$ & Enabling Science and Innovation Required & Impact Potential \\
\hline $\begin{array}{l}\text { Preconstruction } \\
\text { Generation } \\
\text { Estimation }\end{array}$ & $\begin{array}{l}\text { - Advanced high-fidelity modeling to accurately } \\
\text { capture wind plant inflow and wake dynamics } \\
\text { - Accurate ability to calculate energy production } \\
\text { through rigorous risk assessment using } \\
\text { uncertainty quantification } \\
\text { - Quantification of long-term operating wind flow } \\
\text { conditions through verification and validation } \\
\text { campaigns } \\
\text { - Integrated system design for power plants with } \\
\text { improved performance for site-specific } \\
\text { conditions }\end{array}$ & $\begin{array}{l}\text { - Lower FCR through reduced } \\
\text { investor risk, improved } \\
\text { energy estimates, and lower } \\
\text { operational expenditures risk }\end{array}$ \\
\hline
\end{tabular}

The improved wind energy production estimates will provide better quantification of the uncertainty associated with wind energy estimates and lead to improved characterization of overall project risk. These efforts will reduce the variance that is present in current estimates from standard industry tools - tightening the gap between the median estimate (known as P50, wherein $50 \%$ of estimates exceed this estimate) and the worst-case scenario (something closer to 
P99, wherein $99 \%$ of estimates exceed this estimate). This improvement will directly reduce the risk associated with wind power plant investment and could lead to better financing terms (a lower risk premium) for wind power plant developers. Reduced risk driven by a better understanding of the wind plant flow will ultimately lead to a lower FCR and wind plant LCOE.

\subsection{Integrated Wind Power Plant Design, Control, and Operational Strategies}

A2e will enable advanced design, control, and operation of the SMART wind power plant through the combined effort of several focus areas including HFM, verification and validation, wind power plant controls, wind power plant reliability, and integrated system design and analysis. Rather than passively reacting to the flow, the atmosphere drives through the wind power plant, and the wind plant of tomorrow will actively engage with the flow to optimize wind power plant operations for continuously changing operating conditions. With a better understanding of the flow field, novel ways to control both the turbines and the flow through the plant can be developed and implemented.

Returning to the example of wind turbine wakes, the wake itself is a body of flow with reduced energy relative to flow above and around the plant. With precise knowledge of the behavior of these wakes, they can be steered and pushed between turbines and out to plant edges while directing bodies of unwaked flow into the plant so that higher energy flow reaches every turbine in the plant. Through HFM of the wind power plant inflow and wakes coupled with novel wind plant controls and integrated system design, overall energy production of the wind power plant will substantially increase over its lifetime.

Another goal of high-resolution control of wind power plant operation is to more accurately predict and control the loads on major turbine components. Precise knowledge about loading on components will enable significant improvements in diagnostics and prognostics of wind turbine component health. This information can then be included in the optimization of wind power plant operational strategies. Wind power plant operators will be able to predict reliably when major components will need to be serviced and replaced, leading to lower operation and maintenance costs. From a full wind plant perspective, operators of SMART wind power plants will be able to execute real-time mitigation of dangerous turbine component loading that will lead to improved turbine reliability and extended plant lifetime.

All of these factors - increased energy production, improved reliability of turbines and components, lower operation and maintenance costs, and longer plant lifetimes - will lead to substantial reductions in future wind power plant LCOE. The accumulation of knowledge and sophistication around wind plant operation and controls will be used to improve the design of future wind plants. Future wind plants will be designed to leverage new control opportunities around wake steering to potentially place turbines closer together and reduce plant-level costs associated with construction, such as for roads and electricity transmission cables. Specific turbine design, selection, and layout of the wind power plant will be co-optimized with all of the SMART wind power plant control schemes discussed in this section for reductions in LCOE beyond potentially even the lowest expectations of today's experts. Table 2 depicts the relationships between innovation in the SMART wind power plant, the enabling science required, and the impact on $\mathrm{LCOE}$. 
Table 2. Integrated Wind Power Plant Design, Control, and Operational Strategy Interdependencies of Technology Innovations, Scientific Advancements, and Impact Potential

\begin{tabular}{|c|c|c|}
\hline $\begin{array}{l}\text { Technology } \\
\text { Innovation }\end{array}$ & Enabling Science and Innovation Required & Impact Potential \\
\hline $\begin{array}{l}\text { Active Wind Power } \\
\text { Plant Monitoring } \\
\text { and Inflow } \\
\text { Resource Control }\end{array}$ & $\begin{array}{l}\text { Verification and validation campaigns } \\
\text { involving full-field inflow monitoring based on } \\
\text { lidar or similar technology to improve the ability } \\
\text { to design for inflow and dynamic wake effects } \\
\text { - Active wind plant control and high-fidelity } \\
\text { modeling of coupled energy extraction and } \\
\text { turbine load modeling creates improved control } \\
\text { capabilities }\end{array}$ & $\begin{array}{l}\text { - Lower OpEx from reduced } \\
\text { turbine loading and failure } \\
\text { rates } \\
\text { - Improved AEP from energy } \\
\text { capture control }\end{array}$ \\
\hline $\begin{array}{l}\text { Optimized } \\
\text { Operations } \\
\text { Strategies for } \\
\text { Maximizing } \\
\text { Component/ } \\
\text { Turbine Lifetimes }\end{array}$ & $\begin{array}{l}\text { - High-fidelity modeling of the plant that } \\
\text { accurately estimates loading for representative } \\
\text { plant site conditions } \\
\text { - Reliability research into drivers of component } \\
\text { degradation and failure }\end{array}$ & $\begin{array}{l}\text { - Potential lower OpEx from } \\
\text { reduced turbine loading and } \\
\text { failure rates } \\
\text { - Lower OpEx through longer } \\
\text { component life as a result of } \\
\text { controlled degradation of } \\
\text { components } \\
\text { - Lower FCR by increasing } \\
\text { overall plant lifetime }\end{array}$ \\
\hline $\begin{array}{l}\text { Optimum Power } \\
\text { Plant Design and } \\
\text { Turbine } \\
\text { Specification for } \\
\text { Site-Specific Inflow } \\
\text { and Terrain } \\
\text { Conditions }\end{array}$ & $\begin{array}{l}\text { - Advanced high-fidelity modeling to provide } \\
\text { full plant flow modeling that captures multiple } \\
\text { row wake dynamics and atmospheric } \\
\text { entrainment } \\
\text { - Optimized plant integrated system design } \\
\text { based on unique technology selection, layout } \\
\text { configuration, and performance assessment } \\
\text { under site-specific conditions }\end{array}$ & $\begin{array}{l}\text { - Reduced CapEx by advanced } \\
\text { optimization of wind power } \\
\text { plant design } \\
\text { - Improved AEP by active } \\
\text { control manipulation of the } \\
\text { inflow resource through the } \\
\text { wind power plant } \\
\text { - OpEx reduction potential from } \\
\text { improved plant design }\end{array}$ \\
\hline
\end{tabular}

\subsection{Innovative Wind Turbine Machine Design and Technology}

Wind turbines of the future will continue to evolve to become larger, lighter, and more productive machines with larger rotor diameters and taller towers. However, if designers base the future design on today's level of understanding of the complex flows, then cost-reduction and production-enhancement possibilities will be limited. Improving the understanding of the flow physics through A2e will provide more accurate predictions in the wind turbine design process. By applying wisdom gained from the aerospace industry, the wind industry will be able to create machines with advanced controls for improved performance as part of an overall optimized wind power plant. Further, leveraging A2e efforts in HFM, wind power plant controls, and integrated system design will help the next-generation wind turbine designs capture more energy from specific atmospheric conditions and operate as part of an optimized wind power plant system, while having lower overall costs and higher levels of reliability.

A2e efforts will help target innovation in the design process. Current wind turbines and wind power plants are designed with a simplified set of atmospheric conditions intended to encompass all real conditions. This design has two potential pitfalls: (1) the simplified set of atmospheric 
conditions may miss high-risk areas where actual site conditions are more severe, and (2) there may be excessive safety margins in the design in which the simplified conditions are more severe than the actual site conditions. Improving the knowledge of relevant atmospheric conditions for design will result in improved reliability of future wind turbines through better understanding of the most severe conditions affecting design and reduced material usage in which excessive margins currently exist. A2e is anticipated to demonstrate how these factors will lead to lower OpEx and wind power plant capital costs through a combination of its focus areas on HFM, integrated controls, and integrated system design and analysis.

Through innovation in technologies specific to plant-level control coupled with improved design standards, industry will be able to continue the exponential scaling trend that has persisted since the early 1990s to realize wind turbines with even larger rotor diameters and towers. The advancements in A2e around developing validated models of the flow at the heights of interest to these turbines will directly enable industry to pursue such technology advancements. Table 3 depicts the relationships between innovation in wind turbine technology, the enabling science required, and the impact on $\mathrm{LCOE}$.

\section{Table 3. Innovative Wind Turbine Machine Design and Technology Interdependencies of Technology Innovations, Scientific Advancements, and Impact Potential}

\begin{tabular}{|c|c|c|}
\hline $\begin{array}{l}\text { Technology } \\
\text { Innovation }\end{array}$ & Enabling Science and Innovation Required & Impact Potential \\
\hline $\begin{array}{l}\text { Innovative Turbine } \\
\text { Design and Turbine } \\
\text { Controls }\end{array}$ & $\begin{array}{l}\text { - Advanced high-fidelity modeling to capture } \\
\text { rotor wake dynamics from full resolution of } \\
\text { rotating blades } \\
\text { - Assess wake development properties from } \\
\text { dynamic wind plant control strategies (e.g., } \\
\text { yaw, thrust, tilt) } \\
\text { - Assess reliability of novel designs on major } \\
\text { turbine components and enact wind plant } \\
\text { controls against high loads }\end{array}$ & $\begin{array}{l}\text { - Improved AEP from increased } \\
\text { inflow } \\
\text { - CapEx reductions in total } \\
\text { design mass requirements } \\
\text { - Lower OpEx by dissipating } \\
\text { loads and reducing failure rates }\end{array}$ \\
\hline $\begin{array}{l}\text { Standards Evolution } \\
\text { with More Precision } \\
\text { and Fidelity in } \\
\text { Representing } \\
\text { Variable Wind } \\
\text { Turbine and Power } \\
\text { Plant Design } \\
\text { Conditions }\end{array}$ & $\begin{array}{l}\text { - Verification and validation campaigns and } \\
\text { high-fidelity modeling to inform industry } \\
\text { standards development }\end{array}$ & $\begin{array}{l}\text { - CapEx reductions through } \\
\text { reduced excess margins } \\
\text { - OpEx improvements through } \\
\text { more accurate design criteria }\end{array}$ \\
\hline $\begin{array}{l}\text { Large-Scale Wind } \\
\text { Turbines with Large } \\
\text { Rotor Diameters and } \\
\text { Tower Heights }\end{array}$ & $\begin{array}{l}\text { - Advanced high-fidelity modeling to capture } \\
\text { the behavior of wind at very high elevation } \\
\text { above the ground } \\
\text { - Extensive measurement campaigns for } \\
\text { verification and validation of wind behavior } \\
\text { in the upper atmosphere } \\
\text { - Leveraging wind plant control strategies to } \\
\text { reduce loads from operation in the upper } \\
\text { atmosphere }\end{array}$ & $\begin{array}{l}\text { - Improved AEP from operating } \\
\text { at higher heights with } \\
\text { increased inflow } \\
\text { - CapEx reductions through } \\
\text { better characterization of the } \\
\text { load conditions at higher } \\
\text { heights }\end{array}$ \\
\hline
\end{tabular}


Up to this point, the reductions in LCOE tie to advances in conventional wind turbine technology (three-bladed upwind design). The future scenario for reducing wind power plant LCOE discussed in Section 2 also maintains this assumption. It should be noted, however, that the improvements in scientific understanding might enable even more advanced innovations in wind turbine technology. Future wind technology may look different from today's machines and could include fewer blades, multiple rotors per tower, rotation around a vertical rather than a horizontal axis, or even airborne concepts (essentially flying without being affixed to a tower). Although the impacts of such innovations on wind power plant LCOE are harder to define, they may be even greater than those available from innovating the existing dominant design. At the same time, the impact of these technologies on LCOE is highly uncertain. Therefore, this analysis focuses only on the current standard wind turbine technology platform with an upwind, horizontal-axis, three-bladed configuration.

\subsection{Controllable, Dispatchable, and Predictable Grid Support Services}

Although not directly part of the LCOE cost-reduction scenario presented in Section 2, the interaction of wind power plants with the larger electric grid system becomes increasingly important as levels of wind in the system increase. Wind plant power output is variable, changing with the time of day and weather patterns, and uncertain because of the inability to predict the weather with perfect accuracy. These two factors, variability and uncertainty, affect the overall operating cost of the system. However, the variability of wind is reduced over larger areas because of the geographic diversity of the wind resource. Although a single wind turbine's output is highly variable, the aggregated output of a multiturbine wind power plant is less variable and the combined wind power output from a number of plants over a large geographic region is less variable than that of a single wind power plant.

Operation of the power system is affected by a number of different factors including type and flexibility of existing generation (e.g., hydro and gas dispatch differs from that of a coal plant), the amount of variable wind and solar generation, the geographic size of the system, and the frequency with which the power system is dispatched (e.g., 5- or 10-minute intervals versus hourly). Reserves are required to ensure that the varying load is satisfied at all times and to provide for reliable system operation. Ancillary services, such as regulation for short-timescale load following are typically provided by existing gas generators but are services that wind plants will be better equipped to provide in the future. On timescales of hours to days, traditional power plants provide a stable capacity service to the grid, whereas wind currently provides an energy service. On the timescale of months to years, an electric system balancing area will develop a portfolio of resources that can meet both short-term and long-term needs economically and reliably. Up until now, wind power plants have not had the widely demonstrated capability to provide both short- and long-term services to the electric grid; however, with better understanding of the wind resource across scales and advancement in controls and power electronics this will change.

Grid interaction research is not directly funded under A2e, but integrating A2e SMART wind power plant research with ongoing power system research will lead to technological innovations that can achieve increased efficiencies and more reliable power system operation. Research on integrating wind power plant operations for optimizing both the performance of the wind plant 
and grid services will enable cost reductions through fewer forecast errors, advanced wind power plant controls for grid services, and real-time power system cost reductions based on overall system control. By providing these grid services, wind power plants of the future will experience curtailment less frequently, resulting in increased revenue for the plant. Table 4 illustrates the services that the SMART wind power plant can provide to the electric grid system, the improvements enabling those service innovations, and the impact potential of those advances. In this case, the impact potential is not directly affecting LCOE but rather the services the wind power plant can provide to the larger electric grid system.

Table 4. Controllable, Dispatchable, and Predictable Grid Support Service Interdependencies of Technology Innovations, Scientific Advancements, and Impact Potential

\begin{tabular}{|c|c|c|}
\hline Technology Innovation & Enabling Science and Innovation Required & Impact Potential \\
\hline $\begin{array}{l}\text { Grid Services for High } \\
\text { Renewable Energy } \\
\text { Penetration Levels }\end{array}$ & $\begin{array}{l}\text { - Advanced high-fidelity modeling state } \\
\text { estimation for the power system with wind } \\
\text { power plant grid services } \\
\text { - Development of an advanced grid } \\
\text { measurement and sensing system to } \\
\text { integrate wind plants with short-term power } \\
\text { system dispatch } \\
\text { - Integrated high-fidelity modeling to } \\
\text { understand coupled grid performance and } \\
\text { reliability }\end{array}$ & $\begin{array}{l}\text { - Enhanced revenues for } \\
\text { providing short-term grid } \\
\text { services through direct } \\
\text { payments and reduced } \\
\text { curtailment }\end{array}$ \\
\hline $\begin{array}{l}\text { Dispatchability for High } \\
\text { Renewable Energy } \\
\text { Penetration Levels }\end{array}$ & $\begin{array}{l}\text { - Integrated wind plant controls for wind } \\
\text { plant energy production and grid services } \\
\text { - Advanced high-fidelity modeling to } \\
\text { understand plant performance and } \\
\text { reliability }\end{array}$ & $\begin{array}{l}\text { - Reduced wind energy grid } \\
\text { integration cost to system } \\
\text { operators }\end{array}$ \\
\hline $\begin{array}{l}\text { Advanced Forecasting } \\
\text { Techniques for } \\
\text { Dispatch and Unit } \\
\text { Commitment }\end{array}$ & $\begin{array}{l}\text { - Improved forecasting techniques based on } \\
\text { high-fidelity modeling and verification } \\
\text { and validation campaigns } \\
\text { - Integration of "Big Data," high-fidelity } \\
\text { modeling, and atmospheric sensing and } \\
\text { measurement systems }\end{array}$ & $\begin{array}{l}\text { - Reduced wind energy grid } \\
\text { integration cost to system } \\
\text { operators } \\
\text { - Increased revenues through } \\
\text { more accurate energy } \\
\text { forecasts }\end{array}$ \\
\hline $\begin{array}{l}\text { Reduced Uncertainty in } \\
\text { Capacity Value }\end{array}$ & $\begin{array}{l}\text { - Reduced uncertainty in long-term, high- } \\
\text { fidelity modeling predictions }\end{array}$ & $\begin{array}{l}\text { - Reduced need for conventional } \\
\text { generation build-out } \\
\text { - Enhanced revenue in capacity } \\
\text { markets }\end{array}$ \\
\hline
\end{tabular}




\subsection{Summary of LCOE Impacts from Science-Enabled Innovations}

As shown in Figure 5, the integration of these research efforts underlies the ability to realize the SMART wind power plant and significant reductions in the cost of wind energy.

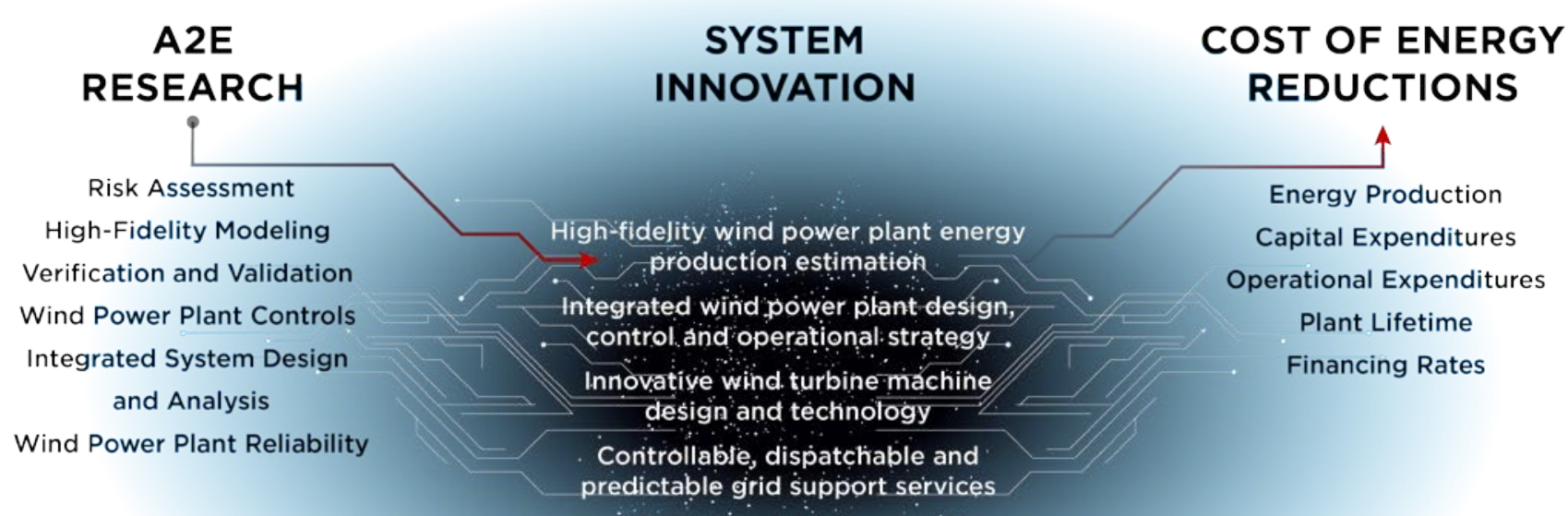

Figure 5. The relationship between A2e research, system innovation, and cost of energy. The collective activities of $A 2 e$ when integrated together will advance wind energy science to enable a spectrum of wind energy innovations (broadly categorized as shown in the graphic). In turn, the innovations, when combined together, will have large impacts on cost of energy parameters from improved energy production to significant reductions in all costs. Illustration by Josh Bauer, NREL

Science investigations to improve understanding of the flow around and within wind power plants will enable optimized wind turbine and power plant design, control, and operation. Scientific advances will enable innovation that leads to improvements in:

- CapEx. The advanced understanding of the atmosphere and wind flow through the plant will enable lower-cost wind turbine technology through: (1) improved design criteria that reflect realistic environmental conditions so that new components can maximize material and structural efficiency, increasing size (such as machine rating, rotor diameter, and hub height), and (2) novel designs for wind turbine technology. These novel designs will involve incremental innovations to existing technology but may depart significantly from the current dominant industry designs and lead to fundamental changes to the whole system.

- AEP. The SMART wind power plant will be designed and built to re-energize flow from above and steer wind turbine wakes to increase productivity of downwind turbines and improve overall plant energy production. In addition, advanced design of the wind power 
plant using high-fidelity simulations and uncertainty quantification will improve the optimization of wind plant layouts for increased energy production over their lifetimes.

- OpEx. Increased accuracy and understanding of uncertainty around wind power plant flows will allow the SMART wind power plant to optimize design and operations to minimize component loads and increase overall reliability. By having an enhanced understanding of the turbine loads and improved design, SMART wind power plant maintenance activities can be optimized to minimize costs. In addition, the advances in knowledge in wind energy science will lead to improvements in turbine design with higher inherent reliability for fewer failures and replacements.

- FCR via financing. The increased accuracy and precise quantification of uncertainty enabled by $\mathrm{A} 2 \mathrm{e}$ for wind plant power performance predictions will reduce project risk and associated financing.

- FCR via plant lifetime. Through advancements in the accuracy of wind plant modeling, the SMART wind power plant will have optimized operations to minimize component loads to extend component, turbine, and overall plant lifetime.

In addition, precisely controlling the wind power plant and obtaining accurate predictions of plant energy production will support a wide range of grid ancillary services as well as short-term and long-term grid operation and production planning. 


\section{The SMART Wind Power Plant Cost of Energy}

Assessing future trends in wind power plant energy costs ties directly to how wind energy contributes to the overall electricity generation mix across the country. Electricity produced from wind power plants in a given region is variable over time; thus, its main value to the electric system is as an energy resource, ${ }^{6}$ thereby offsetting the need for energy production from traditional and potentially more expensive electricity generation units. In other words, wind energy may be primarily considered as a fuel saver. The U.S. Energy Information Administration (EIA) produces regular forecasts of natural gas prices in the Annual Energy Outlook (AEO). Under AEO 2017 reference conditions, levelized fuel costs post-2020 range from approximately $\$ 30 /$ megawatt-hour (MWh) to $\$ 45 / \mathrm{MWh}$ (EIA 2017b). Under low price conditions, fuel costs post-2020 remain below \$30/MWh through 2050.

Achieving further unsubsidized wind costs that are in the range of low future natural gas fuel prices would support large economically competitive deployments of wind power. Driven by A2e research advances and collaboration with industry to develop innovative technologies, the future SMART wind power plant will make wind competitive under all future fuel cost scenarios and approach the lower bound of gas prices between \$20/MWh and \$30/MWh.

Leveraging the innovations described earlier, SMART wind power plants will lower wind plant cost of energy through:

- Scaling the size of the turbine and a range of other advanced innovations to drive down CapEx

- Scaling, along with optimal wind plant design and control, to increase AEP

- Advancing modeling, data analysis, and assimilation to reduce OpEx

- Decreasing financing costs by lowering long-term production risk

- Increasing the wind power plant's lifetime and extending amortization periods.

In addition, from the perspective of integration into the larger electric grid system, plant performance and energy production will be more predictable. The predictability of the SMART wind power plant will support system operators throughout all phases of electric-generation planning. Although this document focuses largely on cost of energy impacts, the impact to grid integration of wind energy is addressed in more detail as well, given its importance. This section details R\&D pathways that entail the SMART wind power plant collection of innovations enabled by advances in science that result in wind energy costs competitive with future fuel

\footnotetext{
${ }^{6}$ An energy resource can best be explained in contrast to a capacity resource. Capacity resources can provide, with high probability, a certain level of energy production on demand so that power system operators can be sure there is enough generation to meet peak electricity demand at any given time. Traditional electricity-generation resources, including fossil-fuel, nuclear, and hydroelectric power plants, are capacity and energy resources to the grid, whereas wind energy is considered to be primarily an energy resource. However, as wind energy technology develops, there is greater potential for wind to serve capacity markets. In addition, wind energy has the potential to become an important resource in ancillary service markets that ensure short-term reliability and stability of the electric grid system.
} 
costs. The analysis is focused on a land-based SMART wind power plant in the year 2030 compared to 2015. However, as previously mentioned, the collection of innovations described are equally applicable to offshore wind power plants and will also drive down future offshore wind energy costs (see Appendix E for recent trends in offshore cost of energy).

\subsection{Cost of Wind Energy Today (2015) and Tomorrow (2030)}

LCOE for current wind projects establishes a baseline for evaluating reductions in future wind power plant costs. In 2015, about 8,500 MW of new wind power plant capacity was installed, comprising 68 distinct projects (Wiser and Bolinger 2016), as illustrated in Figure 6.

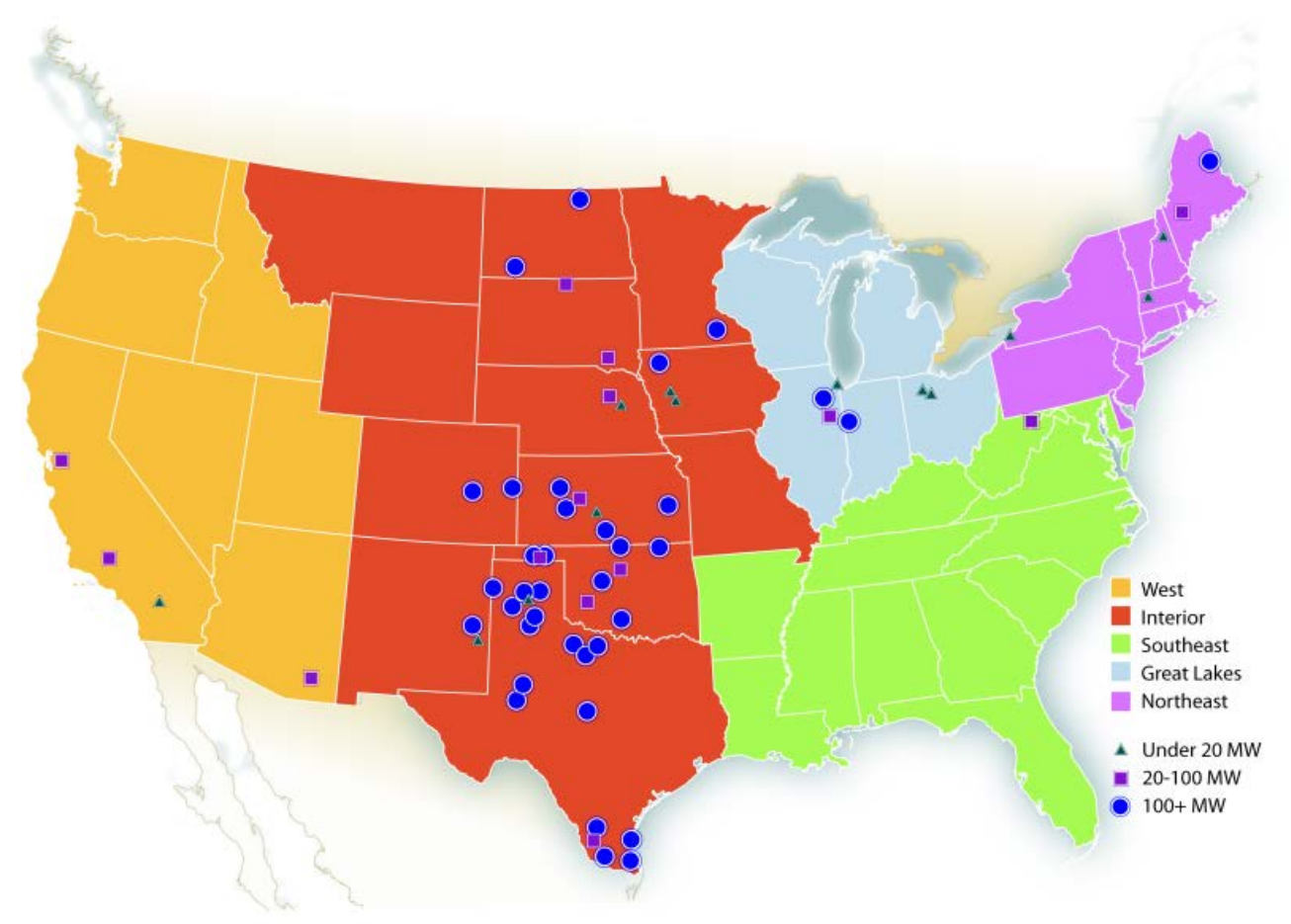

Figure 6. U.S. land-based wind projects installed in 2015. Illustration created using American Wind Energy Association Projects Database, NREL

The wind resource across atmospheric conditions is heterogeneous and depends on geographic location, height above ground, local terrain, and other factors. The LCOE for wind power plant sites will vary based on these differences; thus, it is necessary to analyze LCOE for a range of typical conditions that would occur across diverse regions of the country. For all projects installed in 2015, a median annual average wind speed of 8 meters per second $(\mathrm{m} / \mathrm{s})$ is estimated. ${ }^{7}$ Based on average wind power plant characteristics for 2015 installations in the interior region, five wind power plants were defined to correspond to a range of annual average wind speeds for future U.S. wind power plants (Moné et al. 2017). The range of wind speeds included lower- and upper-bound sites of average annual wind speeds of $5.5 \mathrm{~m} / \mathrm{s}$ and $10 \mathrm{~m} / \mathrm{s}$,

\footnotetext{
${ }^{7}$ Wind power plant geographic locations were associated with long-term average wind resource data created by AWS Truepower; the wind speed estimates do not reflect actual measured wind speeds at a given power plant location and therefore may overestimate or underestimate annual average values.
} 
respectively, as well as $20^{\text {th }}, 50^{\text {th }}$, and $80^{\text {th }}$ percentile wind speed sites, ${ }^{8}$ with average annual wind speeds of $7.4 \mathrm{~m} / \mathrm{s}, 8.0 \mathrm{~m} / \mathrm{s}$, and $8.4 \mathrm{~m} / \mathrm{s}$, respectively. Appendix C includes analysis results for more extreme wind speed sites. Each representative wind power plant included specifications for wind resource and a typical wind turbine configuration for that resource.

For 2030, five representative wind power plants were defined with the same wind resource characteristics as the 2015 plants but with new technology characteristics enabled by incremental advances involving scaling of turbine components and learning as well as advanced innovation through fundamental changes to technology based on scientific discovery and improved understanding of full wind power plant physics. These 2030 scenarios represent an "accelerated R\&D pathway" to the SMART wind power plant.

Specific turbine and plant characteristics for the 2030 accelerated R\&D pathway were established using a combination of expert input, peer-reviewed literature, and NREL plant energy modeling. Building from the workshops that established the innovation groups of the SMART wind power plant, experts were asked to identify specific ranges of potential increases in plant performance (capacity factor, plant life) and reductions in plant costs (CapEx, OpEx, financing) associated with each innovation group. Experts were then asked to develop a particular technology scenario for the SMART wind power plant that included the turbine specifications (rotor diameter, hub height, power rating, specific power) and wind plant energy losses. The NREL Cost and Scaling Model (Fingersh, Hand, and Laxson 2006) was used to estimate future wind plant energy production based on the specified turbine and wind plant losses. Additional insights from a recent high-profile industry survey on the future cost of wind energy (Wiser et al. 2016) were considered to develop cost and performance scenarios for the SMART wind power plant of 2030. Expected future cost of energy was calculated along with a range of uncertainty around the resulting value. For each of the wind power plant concepts, the LCOE analysis takes into account the plant cost and performance as well as financing structures. ${ }^{9}$ Appendix C (financial assumptions) and Appendix D (detailed LCOE calculations) include the full details of the LCOE analysis.

Figure 7 shows the results of the LCOE analysis for an 8-m/s annual average wind speed site (blue) compared to the range of natural gas price projections (grey) and wind cost of energy projections (black line) from AEO 2017 (EIA 2017b). The AEO 2017 wind power plant cost projection reflects modest incremental improvements from current levels associated with the assumed EIA learning rates and wind deployment that occurs in the AEO 2017 reference case. ${ }^{10}$ The R\&D pathway illustrates the potential for accelerated, focused R\&D efforts to improve wind energy science and enable innovations in wind power plant technology. The accelerated R\&D

\footnotetext{
${ }^{8}$ For each new wind project installed in 2015 , an associated wind speed was determined. The $20^{\text {th }}, 50^{\text {th }}$, and $80^{\text {th }}$ percentile wind speed from this population demonstrates the range of wind speed associated with the majority of projects installed in 2015.

${ }^{9}$ The 2015 baseline power plant reflects the likely change to capital structures after current federal policy support structures expire. This change in capital structure and its effects on wind plant weighted-average cost of capital for current and future wind power plants are described in Appendix $\mathrm{C}$ and is shown explicitly in the detailed calculations in Appendix D.

${ }^{10}$ It is important to note that the model used by the AEO 2017 estimates that wind energy deployment after 2020 is reduced substantially because of the assumed inputs and assumptions associated with the AEO 2017 reference scenario.
} 
pathway depends on significant efforts in A2e defined research over the next several years with strong interaction and exchange of information with industry along the way.

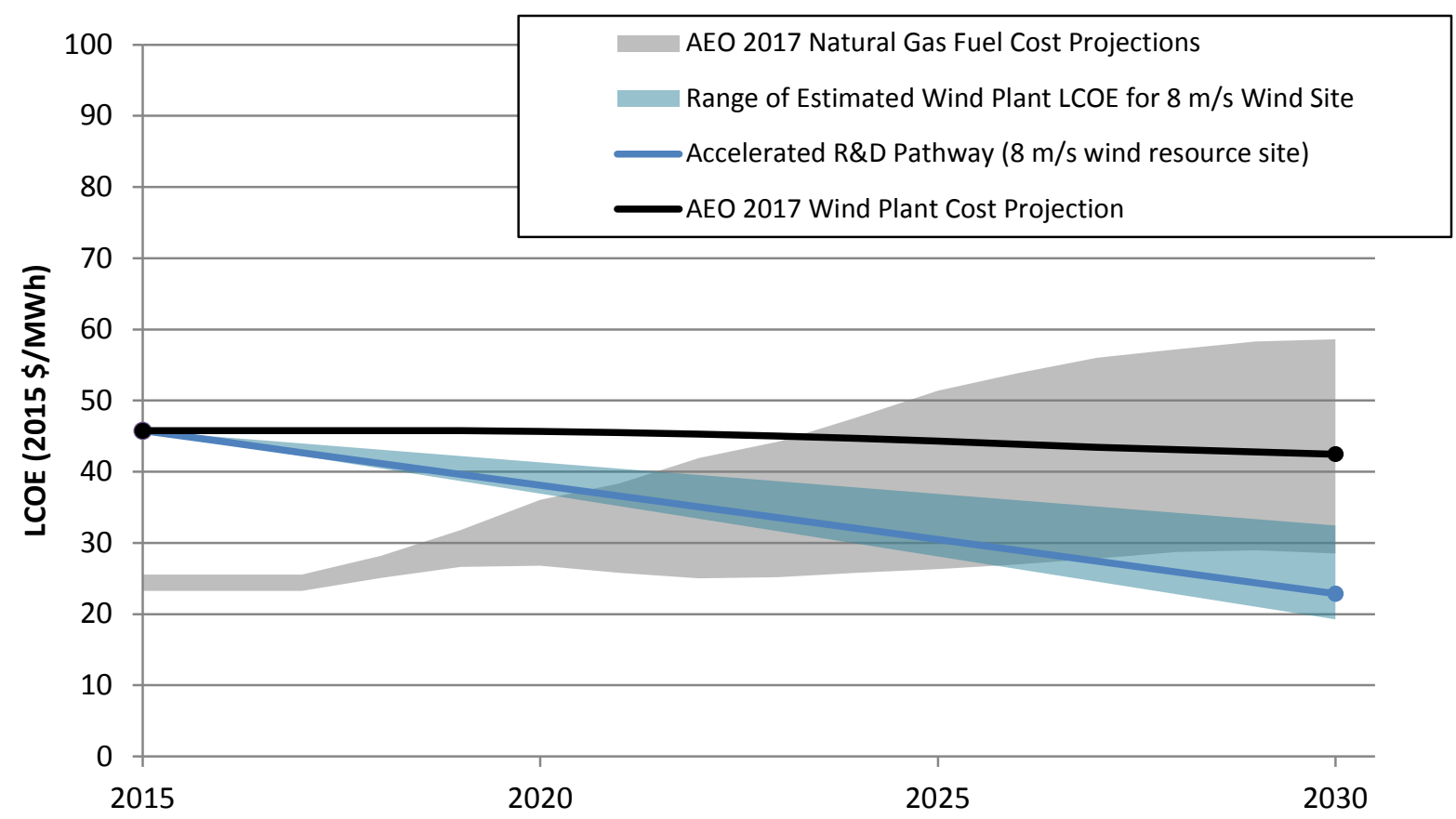

\section{Figure 7. Projected wind power plant costs for the SMART wind power plant using an accelerated R\&D pathway relative to future natural gas prices}

Note: In 2015, a single-point estimate of costs is achieved by using average conditions derived from Moné et al. (2017). The 2030 projections include a range of technology innovation scenarios representing the accelerated R\&D pathway and a range of uncertainty around that projected scenario. Between 2015 and 2030, a linear interpolation is used. The authors recognize that innovation does not occur linearly and the actual pathway will likely be more complex. The AEO 2017 wind power plant cost projection represents a cost-reduction trajectory that is derived from a combination of modeled wind deployment under the AEO reference scenario inputs and assumptions and EIAspecified learning rates; these learning rates include both a minimum learning rate as well as learning associated with robust deployment, when it occurs. As reflected in the slope of this cost-reduction curve, wind energy costs in this specific scenario see only modest incremental technology improvements.

For the accelerated R\&D pathway scenario, wind energy would have a lower cost than natural gas in good wind sites and would be competitive across the country by 2030 . In this scenario, the wind plant LCOE for a location with an $8-\mathrm{m} / \mathrm{s}$ annual wind speed resource is projected to be approximately $\$ 23 / \mathrm{MWh}$ - a value that rivals very low current power plant fuel costs of \$21\$25/MWh (assuming a fuel price of \$3-\$3.5/million British thermal units during January 2017) (EIA 2017a). The illustrated range represents uncertainty around the LCOE estimate given sensitivity to the various inputs. The lower-bound LCOE uses more aggressive technology innovation. The higher-bound LCOE uses a scenario that is based on the current trajectory from today's technology in terms of turbine scale and performance but still leverages advances in scientific knowledge for improved wind power plant performance and cost reductions. Appendix $\mathrm{D}$ provides details of each scenario. The range of LCOE results for the accelerated R\&D pathway span from $\$ 19 / \mathrm{MWh}$ to $\$ 32 / \mathrm{MWh}$. Even if natural gas prices were to remain similar to 
current levels, wind energy could be competitive under the accelerated R\&D pathway anticipated by A2e efforts. Notably, these cost levels are anticipated to be contingent on significant nearterm advancements in the scientific understanding of wind power plant physics commensurate with those projected to be obtained through the A2e research program as well as subsequent industry innovation and technology development.

The significant impact of the "accelerated R\&D pathway" is even more pronounced when considering not just the single wind resource of $8 \mathrm{~m} / \mathrm{s}$ but also the range of wind speeds across sites where wind power plants are typically developed in the United States. Figure 8 illustrates this range of wind power plant LCOE through 2030 for the three characteristic wind speeds identified earlier relative to the range of natural gas price projections from AEO 2017.

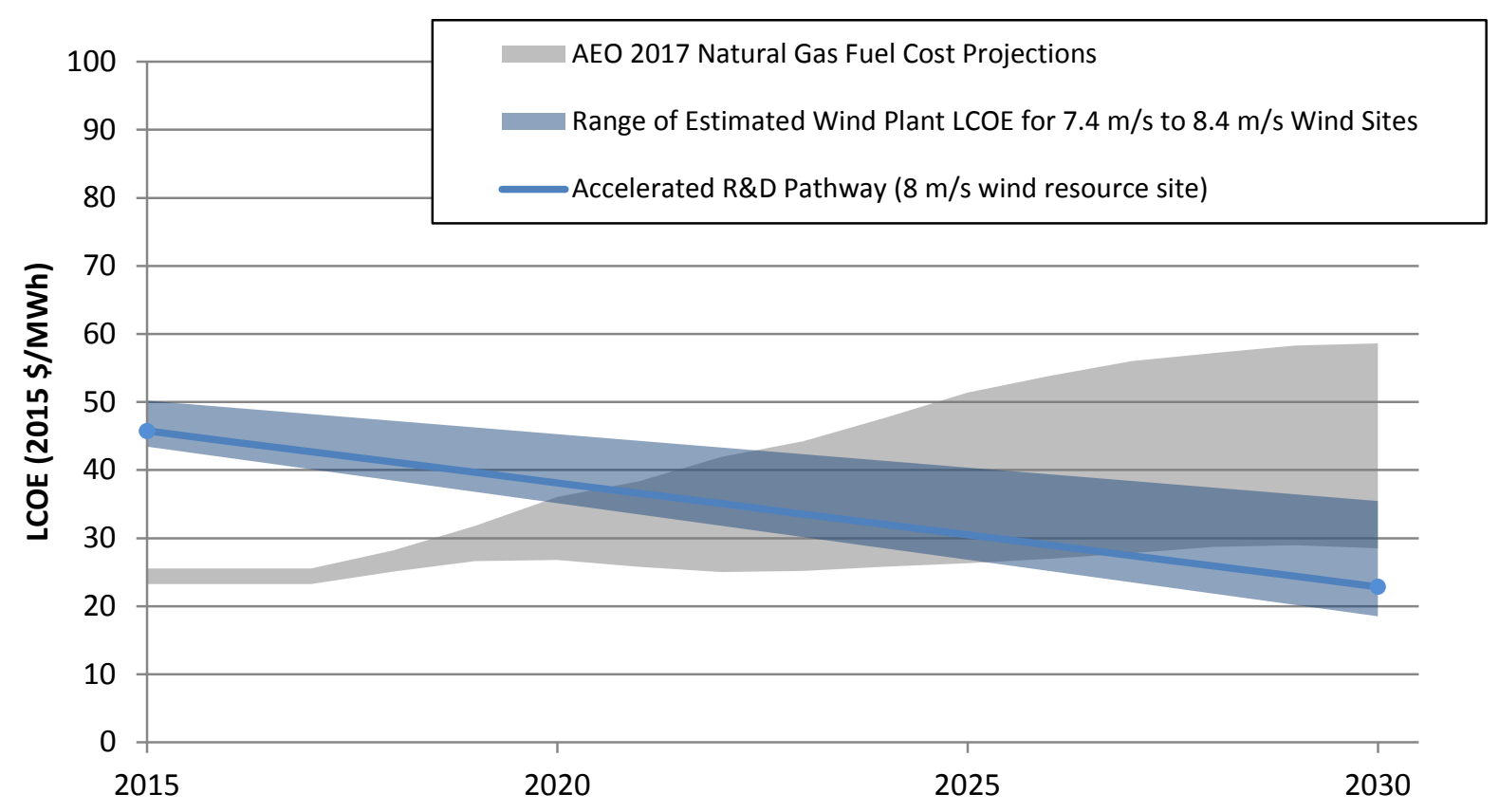

Figure 8. Projected costs for the SMART wind power plant at a range of different wind resource sites using the accelerated R\&D pathway relative to future natural gas prices

Note: The wind speed range in 2015 corresponds to that of $80 \%$ of the projects installed in 2015; the 2030 projections include a range of technology innovation scenarios representing the accelerated R\&D pathway and a range of uncertainty around that projected scenario as well as a range of wind resource conditions. Between 2015 and 2030, a linear interpolation is used. The authors recognize that innovation does not occur linearly and the actual pathway will likely be more complex.

All values within the range from minimum to maximum expected LCOE are lower than the highest projected levelized fuel costs, and in many cases, even the maximum of the range drops below the lowest projected costs. Enabled by A2e efforts and collaboration with industry to develop innovative technologies, even lower wind speed sites across the United States could become competitive with gas-fired electricity generation costs within the projected ranges.

These LCOE projections for the SMART wind power plant in 2030 involve several innovations enabled by advances in scientific knowledge, computing, and consequent innovative technology development. There is an interactive and synergistic effect between the innovations so that the 
2030 LCOE for the accelerated R\&D pathway reflects the combined impact of innovations enabled by A2e wind energy science research. However, the influence of these innovations can be further illuminated by separating the LCOE improvements into constituent improvements in each major LCOE parameter, with the impacts on financing FCR decomposed into the risk reduction in expected wind power plant performance and extended plant life. Applying the multiple technology and LCOE characterization methods described earlier, Figure 9 provides a more detailed illustration of how the accelerated R\&D pathway could lead to a combined reduction in wind power plant LCOE of over $50 \%$.

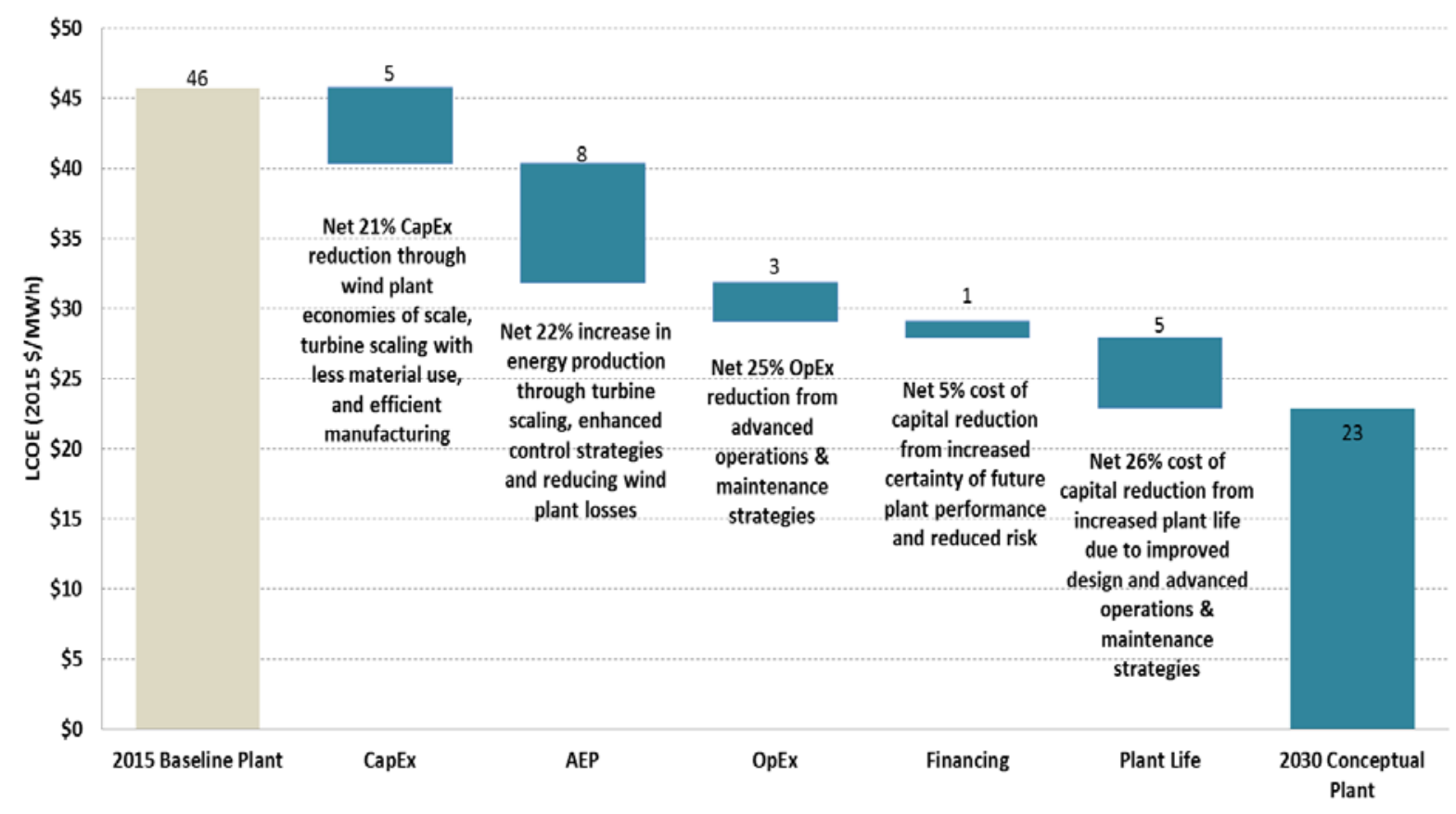

Figure 9. Pathway to $50 \%$ LCOE reduction in 2030 by LCOE parameter

Note: See Appendix D for further details on the primary sources of influence for the cost reduction due to each parameter. In summary, the magnitude of improvements for CapEx, AEP, OpEx, financing, and plant life were derived from expert input, prior literature (e.g., Wiser et al. 2016), and modeled wind power plant performance.

The accelerated R\&D pathway incorporates LCOE reductions resulting from incremental improvements to technology as well as advanced technology based on A2e science-enabled innovations. These cost reductions are broken out by the following LCOE parameters:

- CapEx. The estimated per-unit energy cost reduction of $21 \%$ stems from economic scaling of the size of the turbine, which supports the capture of further turbine and plant economies of scale. The wind turbine industry will continue trends in scaling seen over the past several decades while learning processes will keep the per-unit power costs of these turbines at or below current levels. In addition, the turbine size increases will lead to economies of scale for the wind power plant through reductions in plant infrastructure and erection costs. Science-enabled R\&D pathways in turbine design will push materials and manufacturing costs of per-unit power to levels much lower than those observed today. 
- AEP. Turbine scaling will increase energy production levels relative to today. This scaling will push turbines further into atmospheric conditions that are not well understood, and advances in science will be necessary to design and operate these plants to extract as much power as possible from the incoming wind. These advances will also enable the ability to use novel control mechanisms to further increase AEP through more precise control of the flow through the entire wind power plant. In total, these improvements are projected to increase AEP by $22 \%$.

- OpEx. Through advanced modeling, data analysis, and assimilation, the potential reduction to $\mathrm{OpEx}$ is estimated to be $25 \%$. Operation represents one aspect of the wind power plant that is likely to change fundamentally because of R\&D pathways enabled by the coupling of wind energy science advancements and sophisticated sensing and control of the wind power plant. A precise understanding of the conditions of operation for each wind turbine in the plant will be available over their lifetime with the ability to predict maintenance needs and failures. This information is used in operational strategies to optimize the operation of the power plant not only for maximum energy production but also for maximum energy production at minimum operational costs.

- FCR via financing. Expected decreases in financing costs could reduce LCOE by 5\%. Improvements to wind energy science and the digitization of the wind power plant will reduce the uncertainty associated with projecting the expected performance of a wind power plant over its lifetime. Reducing the uncertainty associated with wind power plant AEP could translate to reduced financing costs for the plant.

- FCR via plant lifetime. A power plant's lifetime is expected to increase to 30 years, supporting a reduction of LCOE by $26 \%$. Achieving this increase in lifetime will require improvements in capability for operations, improved knowledge about design conditions and better turbine technology, and advanced controls.

No single innovation drives a huge change in overall LCOE, but the integrated set of innovations envisioned to be obtainable through advances in wind energy science and realized in the SMART wind power plant will yield total reductions in LCOE of 50\% from current costs and enable large-scale deployments of unsubsidized wind energy nationwide. 


\section{Summary}

To realize a future in which wind energy is cost competitive throughout much of the United States, providing over one-third of the nation's electricity needs, unprecedented advances in the scientific understanding of wind flows down, into, and through the wind power plant are necessary. If left unresolved, uncertainty in the physics of wind power plant operation will undermine the ability to achieve significant reductions in wind cost of energy. Enabled by the DOE A2e applied research program in collaboration with industry, advanced innovation is expected to enable wind plant technologies that provide cost-effective wind power nationwide at $\$ 23 / \mathrm{MWh}$ by 2030 , less than $50 \%$ of the current cost.

A2e wind energy science research will enable these innovations by coupling risk assessment, high- fidelity modeling, verification and validation, wind plant controls, integrated system design and analysis, and wind plant reliability. The structure of the A2e initiative with explicit linkages to industry was created to rectify private sector underinvestment in broad-based scientific advancement while simultaneously using new scientific knowledge and computational capabilities to support private sector technology innovation and commercialization. Accordingly, A2e-derived science will be used to demonstrate the potential of innovation that will lead to the SMART wind power plant of the future. The SMART wind power plant innovations that manage the wind resource in a highly sophisticated and system-level optimized manner affect all major LCOE parameters:

- Improved prediction of wind power plant energy production to reduce investment risk and achieve a lower FCR

- Optimization of the design and operation of SMART wind power plants to extract more wind energy from the plant and increase AEP, reduce loads on turbines for lower OpEx, improve overall upfront design for lower CapEx, and lengthen the plant lifetime for a lower FCR

- Advances in wind turbine and plant technology through highly optimized systems that use better design processes and standards as well as novel designs, both of which will achieve lower CapEx and OpEx

- Improved grid support through precise control of the wind power plant to provide ancillary services, dispatchable electricity, and more certain performance for operations and planning.

In this report, a land-based ${ }^{11}$ future SMART wind power plant that incorporates this collection of innovations was analyzed to understand the potential impact on LCOE for future wind power plants. The resulting accelerated R\&D pathway for an interior U.S. wind site has a potential 2030 LCOE ranging from $\$ 19$ to $\$ 32 / \mathrm{MWh}$ with an expected central value reaching $\$ 23 / \mathrm{MWh}$.

Looking at wind power plants across a range of low to high wind speed sites consistent with sites utilized by the industry in 2015 , the expected central LCOE estimate ranges from $\$ 19$ to \$37/MWh by 2030.

At these cost of energy levels, unsubsidized wind energy will be competitive with natural gas fuel costs throughout much of the country, and wind energy deployments in the United States

\footnotetext{
${ }^{11}$ Future work will also analyze the potential cost reductions for an offshore SMART wind power plant.
} 
could increase to more than $200 \mathrm{GW}$ by 2030 and $500 \mathrm{GW}$ by 2050 , supplying $20 \%$ and $47 \%$, respectively, of U.S. electricity with wind. Relative to a business-as-usual scenario, this investment in technology research and innovation could support as much as $\$ 150$ billion in cumulative electric sector cost savings from 2017 to 2050 (Mai et al. forthcoming). Moreover, these cost levels are expected to enable the deployment levels of the Wind Vision study scenario, leading to considerable benefits for the nation with increased jobs, reduced electricity costs, increased local tax and land-lease revenues, increased domestic manufacturing, reduced electricity sector water use, and significantly reduced electricity sector emissions.

To realize this future, robust, focused scientific research is necessary. A2e is a fundamental research initiative pursuing a solid foundation of scientific understanding and advanced computing capability. Together these advances will enable technology innovation that will provide the bridge from the wind power plant of today to the SMART wind power plant of the future, resulting in cost-competitive wind energy nationwide. 


\section{References}

American Wind Energy Association. 2016. U.S. Wind Industry Third Quarter 2016 Market Report. Released October 20, 2016. Accessed January 2017. http://awea.files.cmsplus.com/FileDownloads/pdfs/3Q2016\%20AWEA\%20Market $\% 20$ Report $\% 20$ Public $\% 20$ Versio n.pdf.

Barr, A. 2016. 2016 Global Wind Turbine Trends. Aarhus, Denmark: MAKE Consulting $\mathrm{A} / \mathrm{S}$. http://www.consultmake.com/ (access to report requires subscription).

Beiter P., W. Musial, A. Smith, L. Kilcher, R. Damiani, M. Maness, S. Sirnivas, T. Stehly, V. Gevorgian, M. Mooney, G. Scott. 2016. A Spatial-Economic Cost-Reduction Pathway Analysis for U.S. Offshore Wind Energy Development from 2015-2030. NREL/TP-6A20-66579. National Renewable Energy Laboratory (NREL), Golden, CO (US). http://www.nrel.gov/docs/fy16osti/66579.pdf.

Bloomberg New Energy Finance. 2016. "Giant Fall in Generating Costs from Offshore Wind." Press release, November 1. Accessed March 20, 2017. https://data.bloomberglp.com/bnef/sites/4/2016/11/BNEF_PR_2016-11-01-LCOE.pdf.

Boersma, S., B. Doekemeijer, P. Gebraad, P. Fleming, J. Annoni, A. Scholbrock, J. Frederik, and J. W. van Wingerden. 2017. "A Tutorial on Control-Oriented Modeling and Control of Wind Farms." Proceedings of the American Control Conference (ACC) 2017, Seattle, Washington.

Bolinger, M. 2015. "Further Development of the A2e/PRUF Bookending Analysis." Internal Presentation. Unpublished.

Bolinger, M. 2017. Internal memo. Unpublished. Feb. 22, 2017.

Clifton, A., A. Smith, and M. Fields. 2016. Wind Plant Preconstruction Energy Estimates: Current Practice and Opportunities. NREL/TP-5000-64735. National Renewable Energy Laboratory (NREL), Golden, CO (US). http://www.nrel.gov/docs/fy16osti/64735.pdf.

Damiani, R. Forthcoming. Perceived Uncertainty Sources in the Wind Power Plant Design. National Renewable Energy Laboratory, Golden, CO (US).

DOE (U.S. Department of Energy). 2015. Wind Vision: A New Era for Wind Power in the United States. DOE/GO-102015-4557. U.S. Department of Energy, Office of Energy Efficiency and Renewable Energy, Washington, D.C. Accessed May 2015. http://www.energy.gov/sites/prod/files/WindVision_Report final.pdf.

DOE. 2017. "Distributed Wind.” DOE, February 6. https://energy.gov/eere/wind/distributedwind.

EIA (U.S. Energy Information Administration). 2017a. "Energy Information Administration (EIA) - Henry Hub Natural Gas Spot Price." Accessed February 6,

2017. https://www.eia.gov/dnav/ng/hist/rngwhhdm.htm. 
EIA. 2017b. Annual Energy Outlook 2017 with Projections to 2050. Washington, D.C.:

EIA. http://www.eia.gov/outlooks/aeo/pdf/0383\%282017\%29.pdf.

Fingersh, L., M. Hand, and A. Laxson. 2006. Wind Turbine Design Cost and Scaling Model. NREL/TP-500-40566. National Renewable Energy Laboratory (NREL), Golden, CO (US). http://www.nrel.gov/docs/fy07osti/40566.pdf.

Fleming, P. A., P. M. O. Gebraad, S. Lee, J. W. van Wingerden, K. Johnson, M. Churchfield, J. Michalakes, P. Spalart, and P. Moriarty. 2014. "Evaluating Techniques for Redirecting Turbine Wakes using SOWFA." Renewable Energy 70: 211-

8. http://dx.doi.org/10.1016/j.renene.2014.02.015.

Fleming, P., J. Annoni, J. J. Shah, L. Wang, S. Ananthan, Z. Zhang, K. Hutchings, P. Wang, W. G. Chen, and L. Chen. 2017. "Field Test of Wake Steering at an Offshore Wind Farm." Wind Energy Science Discussions 2: 229-39. http://dx.doi.org/10.5194/wes-2017-4.

Garlick, R., R. Auckland, B. Zhang. 2017. Market Overview Report - February 2017. 4COffshore Offshore Wind Farm Subscription. Accessed February 2017. http://www.4coffshore.com/ (access to report requires subscription).

Gebraad, P. M. O., F. W. Teeuwisse, J. W. van Wingerden, P. A. Fleming, S. D. Ruben, J. R. Marden, and L. Y. Pao. 2016. "Wind Plant Power Optimization Through Yaw Control Using a Parametric Model for Wake Effects—A CFD Simulation Study." Wind Energy 19: 95-114. doi: 10.1002/we.1822.

Gebraad, P., J. J. Thomas, A. Ning, P. Fleming, and K. Dykes. 2017. "Maximization of the Annual Energy Production of Wind Power Plants by Optimization of Layout and Yaw-Based Wake Control." Wind Energy 20: 97-107. http://dx.doi.org/10.1002/we.1993.

Gilman, P., B. Maurer, L. Feinberg, A. Duerr, L. Peterson, W. Musial, P. Beiter, J. Golladay, J. Stromberg, I. Johnson, D. Boren, and A. Moore. 2016. National Offshore Wind Strategy. DOE/GO-102016-4866. Washington, D.C.: U.S. Department of Energy (DOE), U.S. Department of the Interior (DOI). Accessed January

2017. https://energy.gov/sites/prod/files/2016/09/f33/National-Offshore-Wind-Strategy-report09082016.pdf.

Haupt, S. E., A. Anderson, L. Berg, B. Brown, M. J. Churchfield, C. Draxl, B. L. Ennis, Y. Feng, B. Kosovic, R. Kotamarthi, R. Linn, J. D. Mirocha, P. Moriarty, D. Munoz-Esparza, R. Rai, and W. J. Shaw. 2015. First Year Report of the A2e Mesoscale to Microscale Coupling Project. PNNL-25108. Pacific Northwest National Laboratory (PNNL), Richland, WA (US).

Haupt, S. E., R. Kotamarthi, Y. Feng, J. D. Mirocha, E. Koo, R. Linn, B. Kosovic, B. Brown, A. Anderson, M. J. Churchfield, C. Draxl, E. Quon, W. Shaw, L. Berg, R. Rai, and B. L. Ennis. 2017. Second Year Report of the Atmosphere to Electrons Mesoscale to Microscale Coupling Project: Nonstationary Modeling Techniques and Assessment. PNNL-26267. Pacific Northwest National Laboratory (PNNL), Richland, WA (US). 
Hills, R. G., D. C. Maniaci, and J. W. Naughton. 2015. V\&V Framework. SAND2015-7455. Sandia National Laboratories, Albuquerque, NM.

Jonkman, J. Forthcoming. Workshop on How High-Fidelity Modeling Can Connect to Improvement of Wind Industry Design Capability - Summary Report. National Renewable Energy Laboratory, Golden, CO (US).

Lantz, E., B. Sigrin, M. Gleason, R. Preus, and I. Baring-Gould. 2016. Assessing the Future of Distributed Wind: Opportunities for Behind-the-Meter Projects. NREL/TP-6A20-67337.

National Renewable Energy Laboratory (NREL), Golden, CO

(US). http://www.nrel.gov/docs/fy17osti/67337.pdf.

Lundquist, J. K., A. Clifton, S. Dana, T. Hurges, A. Huskey, P. Moriarty, and J. van Dam. Forthcoming. Instrumentation Atlas. National Renewable Energy Laboratory (NREL), Golden, CO (US).

Mai, T., W. Cole, V. Krishnan, and M. Bolinger. 2015. "Impact of Federal Tax Policy on UtilityScale Solar Deployment Given Financing Interactions (Presentation)." NREL/PR-6A20-65014. National Renewable Energy Laboratory (NREL), Golden, CO (US). Accessed December 2016. http://www.nrel.gov/docs/fy16osti/65014.pdf.

Mai, T., E. Lantz, M. Mowers, and R. Wiser. Forthcoming. The Power of R\&D as a Means for Continued Growth in a Post-PTC World. National Renewable Energy Laboratory (NREL), Golden, CO.

Maniaci, D., and J. Naughton. Forthcoming. "V\&V Integrated Program Planning for Wind Plant Performance.” Sandia National Laboratories, Albuquerque, NM.

Maniaci, D., P. Moriarty, M. Sprague, M. Churchfield, S. Arunajatesan, and M. Barone. Forthcoming. "Atmosphere to Electrons High Fidelity Model Verification and Validation Plan." Sandia National Laboratories, Albuquerque, NM.

Marcy, C., and P. Bieter. 2016. Quantifying the Opportunity Space for Future Electricity Generation: An Application to Offshore Wind Energy in the United States. NREL/TP-6A2066522. National Renewable Energy Laboratory (NREL), Golden, CO. http://www.nrel.gov/docs/fy16osti/66522.pdf.

Moné, C., M. Hand, M. Bolinger, J. Rand, D. Heimiller, and J. Ho. 2017. 2015 Cost of Wind Energy Review. NREL/TP-6A20-66861. National Renewable Energy Laboratory (NREL), Golden, CO (US). http://www.nrel.gov/docs/fy17osti/66861.pdf.

NREL (National Renewable Energy Laboratory). 2016. “Annual Technology Baseline and Standard Scenarios.” National Renewable Energy Laboratory (NREL), Golden, CO (US). Accessed September 2016. http://www.nrel.gov/analysis/data tech baseline.html. 
Peña, A., C. B. Hasager, M. Badger, R. J. Barthelmie, F. Bingöl, J.-P. Cariou, S. Emeis, S. T. Frandsen, M. Harris, I. Karagali, S. E. Larsen, J. Mann, T. K. Mikkelsen, M. Pitter, S. Pryor, A. Sathe, D. Schlipf, C. Slinger, and R. Wagner. 2015. Remote Sensing for Wind Energy. DTU Wind Energy-E-Report-0084. Denmark Technical University, Copenhagen. Accessed June 2017. http://orbit.dtu.dk/files/111814239/DTU_Wind_Energy_Report_E_0084.pdf.

Schreck, S. Forthcoming. Existing Experiment and Test Databases for A2e HFM Model Validation. National Renewable Energy Laboratory (NREL), Golden, CO (US).

Short, W., D. J. Packey, and T. Holt. 1995. A Manual for the Economic Evaluation of Energy Efficiency and Renewable Energy Technologies. NREL/TP-462-5176. National Renewable Energy Laboratory (NREL), Golden, CO. Accessed January

2017. http://www.nrel.gov/docs/legosti/old/5173.pdf.

Sprague, M. A., S. Boldyrev, P. Fischer, R. Grout, W. I. Gustafson Jr., R. Moser, M. Martin, and P. Robinson. 2015. Turbulent Flow Simulation at the Exascale: Opportunities and Challenges Workshop. August 4-5, 2015. Washington, D.C.: DOE. Accessed June 2017. https://science.energy.gov/ /media/ascr/pdf/programdocuments/docs/turb_flow_exascale.p df.

Tusing, R., and J. Fields. 2016. "Atmosphere to Electrons Performance Risk, Uncertainty and Finance (PRUF) Overview (presentation).” Unpublished.

Wiser, R., and M. Bolinger. 2016. 2015 Wind Technologies Market Report. LBNL-1005951. Lawrence Berkeley National Laboratory, Berkeley, CA. Accessed January 2017. https://emp.lbl.gov/publications/2015-wind-technologies-market-report.

Wiser, R., K. Jenni, J. Seel, E. Baker, M. Hand, E. Lantz, and A. Smith. 2016. “Expert Elicitation Survey on Future Wind Energy Costs." Nature Energy 16135. doi:10.1038/NENERGY.2016.135.

Womble, D. E., M. F. Barone, S. W. Hammond, and M. A. Sprague. 2015. A2e High Fidelity Modeling: Strategic Planning Meetings. SAND2015-9499. Sandia National Laboratories, Albuquerque, NM. 


\section{Appendix A. The Atmosphere to Electrons Initiative and Focus Areas}

The text in this appendix is copied from http://a2e.energy.gov.

A2e is a new, multi-year, multi-stakeholder DOE research and development initiative tasked with improving wind plant performance and mitigating risk and uncertainty to achieve substantial reduction in the cost of wind energy production.

The A2e strategic vision will enable a new generation of wind power plant technology, in which SMART wind power plants are designed to achieve optimized performance stemming from more complete knowledge of the inflow wind resource and complex flow through the wind plant.

\section{Focus Areas/Primary Objectives}

The key focus areas of Atmosphere to Electrons (A2e) include the following:

- Performance, risk, uncertainty, and finance: increases the deployment of wind energy by lowering the actual and perceived risks and uncertainties associated with developing, investing in, owning, and operating wind power plants

- High-fidelity modeling, verification, and validation: uses high-performance, massively parallel computers to understand and accurately model fundamental physics on appropriate temporal and spatial scales to predict complex, rapidly changing inflow to the wind plant, complex flow within the plant, and individual turbine and wind plant responses (as a whole) to the flows, as well as provide credible assessment of computational accuracy and uncertainty within a verification and validation paradigm

- Aeroacoustics: focuses on understanding the fundamental mechanisms of wind power plant noise generation, propagation, and reception through new science, technology, and education to answer critical questions, address public concerns about wind turbine noise, provide additional physics-based data required for regulators to establish sound policies, and enable development of practical noise-reduction methods and technologies

- Integrated wind plant control: focuses on developing the technical capabilities, methods, and approaches to enable "smart" plant control design to optimize wind power plants for both land-based and offshore applications

- Integrated system design and analysis: enables full life cycle, site-specific, cost-of-energy wind power plant optimization by providing a comprehensive analysis capability for landbased and offshore wind plants; coordinating development of open-source, baseline analysis modules; developing and disseminating methods to accurately generate wind power plant design criteria; and incorporating a new wind plant optimization approach into international standards

- Reliability: provides reliable, lower-cost electricity delivery by increasing inherent reliability and reducing remaining useful life uncertainty, as well as addressing fundamental industrywide technology barriers and knowledge gaps that impede progress 
- Data archive and portal: provides initiative participants and data users with a distributed system - a "Wind Cloud"- that functions as a repository for all A2e data. This Wind Cloud will be accessible via an open, secure, and easy-to-navigate user interface that facilitates community data access, interaction, and collaboration. 


\section{Appendix B. Levelized Cost of Energy Equation}

The equation used to calculate the levelized cost of energy (LCOE) is derived from Short et al. (1995) and the National Renewable Energy Laboratory's (NREL's) Annual Technology Baseline (NREL 2016). The key variables for the calculation are shown in Table B-1.

Table B-1. Summary of Variables in LCOE Calculation

\begin{tabular}{|c|c|c|c|}
\hline \multirow{12}{*}{ 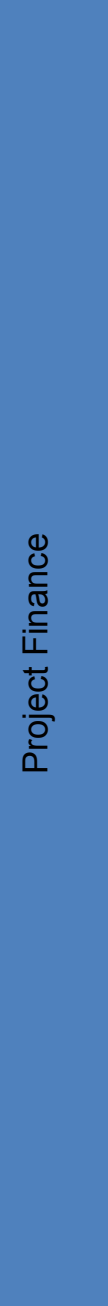 } & Symbol & Name & Definition \\
\hline & $t$ & $\begin{array}{l}\text { Economic Lifetime } \\
\text { (years) }\end{array}$ & $\begin{array}{l}\text { Length of time for paying off assets ( } 20 \text { years for all } \\
\text { technologies) }\end{array}$ \\
\hline & $D F$ & Debt Fraction & $\begin{array}{l}\text { Fraction of capital financed with debt; } 1-D F \text { is assumed } \\
\text { financed with equity ( } 50 \% \text { for all technologies) }\end{array}$ \\
\hline & $R R O E$ & $\begin{array}{l}\text { Rate of Return on } \\
\text { Equity (real) }\end{array}$ & $\begin{array}{l}\text { Assumed rate of return on the share of assets financed } \\
\text { with equity ( } 10 \% \text { real/ } 13 \% \text { nominal for all technologies) }\end{array}$ \\
\hline & $I R$ & Interest Rate (real) & $\begin{array}{l}\text { Assumed interest rate on debt }(5.4 \% \mathrm{real} / 8 \% \text { nominal } \\
\text { for all technologies) }\end{array}$ \\
\hline & $i$ & Inflation Rate & Assumed inflation rate based on historical data $(2.5 \%)$ \\
\hline & $T R$ & Tax Rate & Combined state and federal tax rate $(40 \%)$ \\
\hline & $M$ & $\begin{array}{l}\text { Depreciation Period } \\
\text { (years) }\end{array}$ & $\begin{array}{l}\text { Number of years in the Modified Accelerated Cost } \\
\text { Recovery System depreciation schedule (five for wind } \\
\text { plants) }\end{array}$ \\
\hline & $F D$ & Depreciation Fraction & $\begin{array}{l}\text { Fraction of capital depreciated in each year, } 1 \text { to } M \\
(20 \%, 32 \%, 19.2 \%, 11.5 \%, 11.5 \% \text {, and } 5.76 \% \text { for wind } \\
\text { power plants })\end{array}$ \\
\hline & $C R F$ & $\begin{array}{l}\text { Capital Recovery } \\
\text { Factor }\end{array}$ & $\begin{array}{l}\text { The ratio of a constant annuity to the present value of } \\
\text { receiving that annuity for a given length of time }(8.89 \% \\
\text { real/ } 10.9 \% \text { nominal); CRF is a function of WACC and } t\end{array}$ \\
\hline & $W A C C$ & $\begin{array}{l}\text { Weighted-Average } \\
\text { Cost of Capital (real) }\end{array}$ & $\begin{array}{l}\text { The average expected rate that is paid to finance } \\
\text { assets }(6.2 \% \text { reall } 8.9 \% \text { nominal }) ; W A C C \text { is a function } \\
\text { of } D F, R R O E, I R, i \text {, and } T R\end{array}$ \\
\hline & ProFinFactor & Project Finance Factor & $\begin{array}{l}\text { Technology-specific financial multiplier to account for } \\
\text { the taxes and depreciation (1.137); ProFinFactor is a } \\
\text { function of } T R, W A C C, i, M \text {, and FD }\end{array}$ \\
\hline \multirow{4}{*}{ 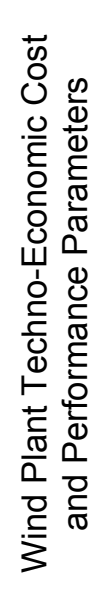 } & $O p E x$ & $\begin{array}{l}\text { Operation and } \\
\text { Maintenance } \\
\text { Expenses (\$/MW- } \\
\text { year) }\end{array}$ & $\begin{array}{l}\text { Annual expenditures to operate and maintain } \\
\text { equipment that are incurred on a per-unit-capacity } \\
\text { basis }\end{array}$ \\
\hline & $A E P_{\text {net }}$ & $\begin{array}{l}\text { Net Annual Energy } \\
\text { Production } \\
\text { (MWh/MW/yr) }\end{array}$ & $\begin{array}{l}\text { The amount of energy produced in a given year per } \\
\text { megawatt capacity after system losses and availability } \\
\text { are taken into account }\end{array}$ \\
\hline & CapEx & Installed Capital Cost & $\begin{array}{l}\text { Total capital expenditure (CapEx) to achieve } \\
\text { commercial operation up to the plant gate }\end{array}$ \\
\hline & $F C R$ & Fixed Charge Rate & $\begin{array}{l}\text { A coefficient that captures the average annual carrying } \\
\text { charges including return on installed capital, } \\
\text { depreciation, and corporate income taxes; FCR is a } \\
\text { function of ProFinFactor and CRF }\end{array}$ \\
\hline
\end{tabular}


Then, the LCOE is computed as follows:

$$
\begin{gathered}
L C O E=\frac{F C R * C A P E X+O P E X}{\left(\mathrm{AEP}_{\text {net }} / 1,000\right)} \\
F C R=C R F * \text { ProFinFactor } \\
\text { CRF }=\frac{\text { WACC }-1}{1-\left(\frac{1}{\text { WACC }}\right)^{t}} \\
\text { WACC }=\frac{(1+[(1-D F)(R R O E * i-1)]+[D F(I R * i-1)(1-T R)])}{i} \\
\text { ProFinFactor }=\left(\frac{1-T R * P V D}{1-T R}\right) \\
P V D=\sum_{y=1}^{M+1} F D_{y} f_{y} \\
f_{y}=\frac{1}{d^{y}} \\
d=W A C C * i
\end{gathered}
$$




\section{Appendix C. Estimating the Fixed Charge Rate}

The simplified LCOE equation described in Appendix B uses a fixed charge rate (FCR) to represent the capital structure of a project. By assuming that operational expenditures ( $\mathrm{OpEx})$ and annual energy production (AEP) are constant over time, a standard capital recovery factor (CRF) can be calculated. The real, after-tax weighted-average cost of capital (WACC) is used as the discount rate in the CRF equation. The FCR includes the CRF, corporate income taxes, and depreciation.

To estimate the cost of capital for wind plants, in terms of an FCR, a number of assumptions are required. However, the project design life and the WACC are the two variables that distinguish one capital structure from another. Other variables, such as those defining depreciation and corporate tax rates, are held constant. Four capital structures shown in Table C-1 were developed to reflect different concepts as follows:

- Typical 2015 capital structure. This capital structure is based on the 2015 Cost of Wind Energy Review (Moné et al. 2017) utilizing the WACC estimated by the Lawrence Berkeley National Laboratory as "average" in the United States in 2015. This capital structure is typical in 2015 for project investors that intend to take advantage of the production tax credit (PTC).

- Post-PTC capital structure. This capital structure reflects a likely shift toward an increased debt fraction that may be realized as the PTC ramps down and expires in 2020 (Mai et al. 2015).

- Post-PTC with A2e risk-reduction capital structure. Analysis conducted to explore the potential impact of reducing performance risk on debt fraction, debt rates, and equity rates suggests that the most likely impact will be to increase debt fraction. Based on this work (Bolinger 2015, 2017; Tusing and Fields 2016), an estimated WACC reduction of 50 basis points was derived.

- Post-PTC with A2e risk-reduction and extended power plant life capital structure. This approach increases the amortization period for which capital recovery occurs from 20 years to 30 years.

Table C-1. Project Capital Structure Representation

\begin{tabular}{|l|c|c|c|c|}
\hline \multicolumn{1}{|c|}{ Financing } & $\begin{array}{c}\text { Typical } \\
\mathbf{2 0 1 5} \\
\text { Capital } \\
\text { Structure }\end{array}$ & $\begin{array}{c}\text { Post-PTC } \\
\text { Capital } \\
\text { Structure }\end{array}$ & $\begin{array}{c}\text { Post-PTC with } \\
\text { A2e Risk- } \\
\text { Reduction Capital } \\
\text { Structure }\end{array}$ & $\begin{array}{c}\text { Post-PTC with A2e Risk- } \\
\text { Reduction and Extended } \\
\text { Plant Life Capital Structure }\end{array}$ \\
\hline $\begin{array}{l}\text { Project Design Life } \\
\text { (Years) }\end{array}$ & 20 & 20 & 20 & 30 \\
\hline $\begin{array}{l}\text { WACC (Nominal; After } \\
\text { Tax) }\end{array}$ & $8.3 \%$ & $5.6 \%$ & $5.1 \%$ & $5.1 \%$ \\
\hline WACC (Real; After Tax) & $5.6 \%$ & $3.1 \%$ & $2.6 \%$ & $2.6 \%$ \\
\hline $\begin{array}{l}\text { Real Fixed Charge Rate } \\
\text { (\%) }\end{array}$ & $9.6 \%$ & $7.4 \%$ & $7.0 \%$ & $5.2 \%$ \\
\hline
\end{tabular}

Note: Tan highlights illustrate changes as a result of input assumptions 


\section{Appendix D. Cost of Energy Estimate Details}

Estimating the cost of energy for current and future wind power plants requires specifying the wind power plant technical and financial parameters. This process includes the wind power plant size and wind resource, key configuration parameters of the turbine, and assumptions about the project capital structure as discussed in Appendix C.

Based on average wind power plant characteristics for 2015 installations in the interior region of the United States, five representative wind plants were defined to correspond to the full range of wind speeds that future U.S. wind plants could experience. In 2015, the wind projects installed in the interior region, on average, used turbines with 2 megawatts (MW) of rated capacity, rotor diameters of 102 meters (m), and hub heights of $80 \mathrm{~m}$. The wind power plants themselves had, on average, overall capital expenditures (CapEx) of $\$ 1,640 /$ kilowatt $(\mathrm{kW})$ (Wiser and Bolinger 2016). An approximate estimation of the annual energy production for a wind plant of this scale in an 8-meter-per-second $(\mathrm{m} / \mathrm{s})$ annual average wind speed location is 3,767 megawatt-hour $(\mathrm{MWh}) / \mathrm{MW} / \mathrm{yr}$ (with a resulting capacity factor of $43 \%$ ). OpEx for this representative plant are an estimated $\$ 51 / \mathrm{MW} / \mathrm{yr}$.

There are two primary ways that a wind power plant owner offsets the annualized LCOE: 1) power purchase agreements, which contract a certain price per megawatt-hour of electricity generation over a certain time period, and 2) the PTC available for a period of 10 years from the point at which a wind plant becomes operational. ${ }^{12}$ Based on current legislation, the PTC is available for projects that begin construction before 2020 but will no longer be available for projects that begin in 2020 or later.

The PTC also affects an overall wind project LCOE in terms of the financing structure. Such project capital structures rely on higher cost equity partners than what might be expected in an environment in which the PTC is not available. Because the PTC is phasing out by 2020, this analysis assumes a project capital structure based on characteristics that are likely to be present after it expires-nominally an increase in the debt fraction of the capital structure. The average WACC for projects installed in 2015 in the United States was $8.3 \%,{ }^{13}$ and these projects would have utilized the PTC. An increase in the debt fraction of the project capital structure in a postPTC environment results in a project capital structure with a nominal WACC of $6.7 \%$. LCOE values reflecting 2015 conditions were calculated using both project capital structures for comparison (see Appendix B for project capital structure details).

LCOE values are shown in Table D-1 for each of the five representative U.S. wind resource regions for each capital structure. These results are calculated using wind power plant specifications mentioned earlier and the methodology and assumptions described in Appendix B and Appendix C.

\footnotetext{
12 "In December 2015, Congress passed a 5-year phased-down extension of the PTC. To qualify, projects must begin construction before January 1, 2020. In May 2016, the IRS issued favorable guidance allowing 4 years for project completion after the start of construction, without the burden of having to prove continuous construction. In extending the PTC, Congress also included a progressive reduction in the value of the credit for projects starting construction after 2016. Specifically, the PTC will phase down in increments of 20 percentage points per year for projects starting construction in 2017 (80\% PTC), 2018 (60\%), and 2019 (40\%)" (Wiser and Bolinger 2016).

${ }^{13}$ Estimates created by Lawrence Berkeley National Laboratory for inclusion in the International Energy Agency Wind Task 26 project statistics update (to be published online).
} 
Table D-1. 2015 Land-Based Wind Plant Characteristics

\begin{tabular}{|c|c|c|c|c|c|}
\hline \multirow[b]{2}{*}{$\begin{array}{l}\text { Average Annual Wind Speed }(\mathrm{m} / \mathrm{s}) \text { at } 80-\mathrm{m} \\
\text { Hub Height }\end{array}$} & \multicolumn{5}{|c|}{$\begin{array}{l}\text { Wind Plant Characteristics Associated with Average } \\
\text { Wind Speed }\end{array}$} \\
\hline & $<=5.5$ & 7.4 & 8.0 & 8.4 & $>=10$ \\
\hline Specific Power $\left(\mathrm{W} / \mathrm{m}^{2}\right)$ & 200 & 237 & 245 & 255 & 325 \\
\hline Machine Rating (MW) & 2 & 2 & 2 & 2 & 2 \\
\hline Rotor Diameter (m) & 113 & 104 & 102 & 100 & 89 \\
\hline Hub Height (m) & 80 & 80 & 80 & 80 & 80 \\
\hline CapEx (\$/kW) & 1,735 & 1,653 & 1,640 & 1,623 & 1,539 \\
\hline OpEx (\$/kW/year) & 51 & 51 & 51 & 51 & 51 \\
\hline Capacity Factor & $27 \%$ & $39 \%$ & $43 \%$ & $45 \%$ & $49 \%$ \\
\hline $\begin{array}{l}\text { FCR (Typical } 2015 \text { Capital Structure); } \\
\text { Nominal/Real WACC = 8.3\%/5.6\% }\end{array}$ & $9.6 \%$ & $9.6 \%$ & $9.6 \%$ & $9.6 \%$ & $9.6 \%$ \\
\hline $\begin{array}{l}\text { FCR (Post-PTC Capital Structure); } \\
\text { Nominal/Real WACC = 5.6\%/3.1\% }\end{array}$ & $7.4 \%$ & $7.4 \%$ & $7.4 \%$ & $7.4 \%$ & $7.4 \%$ \\
\hline LCOE - Typical 2015 Capital Structure (\$/MWh) & 93 & 61 & 55 & 52 & 47 \\
\hline LCOE - Post-PTC Capital Structure (\$/MWh) & 77 & 50 & 46 & 43 & 39 \\
\hline
\end{tabular}

This analysis considered a few different parameters than those considered for the 2015 Cost of Wind Energy Review to calculate LCOE (Moné et al. 2017). The most significant difference between this analysis and the review is the capital finance structure. This revised structure assumes a lower debt interest rate and higher return on equity, as described earlier. This analysis utilizes the range of wind power plant technology associated with wind speeds and based on the interior region of the country included in the 2015 Cost of Wind Energy Review rather than relying solely on the single reference project. The reference project is intended to reflect national average wind power plant costs associated with wind resource characteristics consistent with prior reports. The reference project assumes a $7.75-\mathrm{m} / \mathrm{s}$ average wind speed at $80 \mathrm{~m}$ above ground level, which corresponds to a capacity factor of $40 \%$. The median wind speed for 2015 project installations is $8.0 \mathrm{~m} / \mathrm{s}$, which corresponds to a capacity factor of $43 \%$. The reference project is based on the capacity-weighted average CapEx for all 2015 projects, $\$ 1,690 / \mathrm{kW}$, whereas the capacity-weighted average CapEx for 2015 projects installed in the interior of the country was $\$ 1,640 / \mathrm{kW}$. The OpEx and operational life remain the same. Table D-2 compares the results for the baseline wind power plant with the reference project in the 2015 Cost of Wind Energy Review (Moné et al. 2017). 
Table D-2. Comparison of the 2015 Baseline Wind Power Plant with the Reference Project in the 2015 Cost of Wind Energy Review

\begin{tabular}{|lcc|} 
& $\begin{array}{c}\text { 2015 Reference Project } \\
\text { (2015 Cost of Wind } \\
\text { Energy Review) }\end{array}$ & 2015 Baseline Plant \\
\hline CapEx (\$/kW) & 1,690 & 1,640 \\
\hline OpEx (\$/kW/year) & 51 & 51 \\
\hline Capacity Factor (\%) & 40 & 43 \\
\hline Net AEP (MWh/MW/year) & 3,494 & 3,767 \\
\hline $\begin{array}{l}\text { Wind Speed (at 80-m Hub Height) } \\
\text { [m/s] }\end{array}$ & 7.75 & 8.00 \\
\hline Real WACC (\%) & 5.7 & 3.1 \\
\hline Plant Life (years) & 20 & 20 \\
\hline Real FCR (\%) & 9.6 & 7.4 \\
\hline LCOE (\$MWh) & 61 & 46 \\
\hline
\end{tabular}

Note: $7.5 \mathrm{~m} / \mathrm{s}$ at $50-\mathrm{m}$ hub height is equal to $8 \mathrm{~m} / \mathrm{s}$ at $80-\mathrm{m}$ hub height

Note: $7.25 \mathrm{~m} / \mathrm{s}$ at $50-\mathrm{m}$ hub height is equal to $7.75 \mathrm{~m} / \mathrm{s}$ at $80-\mathrm{m}$ hub height

Using the method and baseline as described for a post-PTC scenario, the analysis estimated an LCOE range across wind speeds for projects in 2030. Turbine parameters developed for the accelerated R\&D pathway (3.25-MW turbine rating, 144-m rotor diameter, 135-m hub height) reflect the wind power plant associated with the $8-\mathrm{m} / \mathrm{s}$ annual average wind speed. The range of specific power across the five representative plants in 2030 is the same as the range defined to reflect the best wind turbine technology available in 2016: $60 \mathrm{~W} / \mathrm{m}^{2}$ (Barr 2016). Similarly, the CapEx estimate associated with the accelerated R\&D pathway is related to the $8-\mathrm{m} / \mathrm{s}$ wind speed wind power plant. The range of CapEx across the five representative plants is equivalent to that defined to reflect wind plants in 2015-about $\$ 200 / \mathrm{kW}$. The LCOE values for 2030 estimates use the post-PTC capital structure as modified to reflect the accelerated R\&D pathway advances in risk-reduction and extended plant life.

Table D-3. Projected 2030 Land-Based Wind Plant Characteristics for the Accelerated R\&D Pathway

Wind Plant Characteristics Associated with Average Wind Speed

\begin{tabular}{|c|c|c|c|c|c|}
\hline Average Annual Wind Speed $(\mathrm{m} / \mathrm{s})$ at $80-\mathrm{m}$ hub height & $<=5.5$ & 7.4 & 8.0 & 8.4 & $>=10$ \\
\hline Specific Power (W/m2)* & 170 & 193 & 200 & 205 & 240 \\
\hline Machine Rating (MW) & 3.25 & 3.25 & 3.25 & 3.25 & 3.25 \\
\hline Rotor Diameter (m) & 156 & 147 & 144 & 142 & 131 \\
\hline Hub Height (m) & 135 & 135 & 135 & 135 & 135 \\
\hline CapEx $(\$ / k W)$ & 1,395 & 1,313 & 1,300 & 1,283 & 1,199 \\
\hline OpEx (\$/kW/year) & 38 & 38 & 38 & 38 & 38 \\
\hline Capacity Factor & $34 \%$ & $49 \%$ & $53 \%$ & $55 \%$ & $60 \%$ \\
\hline \multicolumn{6}{|l|}{ FCR (Post-PTC with A2e Risk Reduction and Extended } \\
\hline $\begin{array}{l}\text { Plant Life Capital Structure); Nominal/Real WACC = } \\
5.1 \% / 2.6 \%\end{array}$ & $5.2 \%$ & $5.2 \%$ & $5.2 \%$ & $5.2 \%$ & $5.2 \%$ \\
\hline $\begin{array}{l}\text { LCOE - Post-PTC w/A2e Risk Reduction and Extended } \\
\text { Plant Life Capital Structure (\$/MWh) }\end{array}$ & 37 & 25 & 23 & 22 & 19 \\
\hline
\end{tabular}

*Assume specific power is linear across wind speed and range similar to 2-MW best in class available in 2016 
The range of LCOE across wind speeds in 2030 ( $\$ 19 / \mathrm{MWh}-\$ 37 / \mathrm{MWh}$ from wind speeds less than $5.5 \mathrm{~m} / \mathrm{s}$ to more than $10 \mathrm{~m} / \mathrm{s})$ is reduced from that in $2015(\$ 39 / \mathrm{MWh}-\$ 77 / \mathrm{MWh}$ across the same wind speed range) primarily through the overall reduction in specific power and the assumption that $R \& D$ advances increase power plant energy production for similar wind speed locations.

The pathway from a wind plant reflecting typical characteristics of those installed in 2015 in the interior region to a wind plant installed in a similar wind resource location in 2030 was developed in multiple steps. In some cases, simple models were used to estimate the impact of potential innovations. In other cases, expert input was used to provide the basis for estimating R\&D impacts. The primary innovations modeled are:

- Increased energy capture through turbine scaling. This is modeled assuming the following wind turbine parameters: $3.25-\mathrm{MW}$ machine rating, $144-\mathrm{m}$ rotor diameter, and $135-\mathrm{m}$ hub height. These turbine parameters were determined assuming a range of specific power commensurate with "best-in-class" 2-MW machines available in 2016 (Barr 2016) but at a scale of 3.25 MW, as envisioned by the experts in Wiser et al. (2016) for the median 2030 turbine technology. Energy production is calculated for an $8-\mathrm{m} / \mathrm{s}$ (at $80-\mathrm{m}$ height) wind speed with a Weibull distribution $(\mathrm{k}=2$, shear exponent $=0.14)$ using NREL's Cost and Scaling Model.

- Increased energy production through wind power plant optimization. This is modeled by assuming that losses within the wind power plant, estimated at $15 \%$ for the 2015 baseline plant, are reduced by $50 \%$ based on expert input.

- CapEx reduction through wind turbine control and component design to maximize material use. This is modeled by assuming a percent reduction consistent with the median value for the low scenario from Wiser et al. (2016).

- OpEx reduction through optimized power plant operation. This is modeled by assuming a percent reduction based on expert input.

- Reduced investor risk resulting from greater certainty in lifetime wind plant energy production and operation costs. This is modeled using the WACC associated with the postPTC with A2e risk-reduction capital structure defined earlier.

- Extended plant life resulting from the ability to control operation within precise design limits and overall plant optimization based on detailed inflow measurements. This is modeled using the post-PTC with A2e risk-reduction and extended plant life capital structure defined earlier.

In addition to the accelerated R\&D pathway, higher and lower cost of energy pathways were included to provide a range of possible outcomes. The higher level is based on Wiser et al. (2016) median values for the median scenario (50\% probability). This scenario represents perspectives from wind industry experts for future technology development assuming continued deployment, R\&D, and industry maturation. The accelerated R\&D pathway, as described earlier, represents independently derived LCOE component values to reflect possible advances associated primarily with significantly improved knowledge of the flow within and around wind plants. The lower-level LCOE estimate reflects similar component-level advances further informed by expert input and includes increased annual energy production resulting from 
additional turbine scaling to machine ratings of $5 \mathrm{MW}$ with 200-m rotor diameters and 150-m hub heights, further reduction of wind plant losses, and lower CapEx. The parameters that are varied across wind speed for the higher and lower cost of energy pathways are shown in Table D-4 and Table D-5.

Table D-4. Projected 2030 Land-Based Wind Power Plant Characteristics for the Lower LCOE Range

\begin{tabular}{|c|c|c|c|c|c|}
\hline \multirow[b]{2}{*}{$\begin{array}{l}\text { Average Annual Wind Speed }(\mathrm{m} / \mathrm{s}) \text { at } 80-\mathrm{m} \text { Hub } \\
\text { Height }\end{array}$} & \multicolumn{5}{|c|}{$\begin{array}{c}\text { Wind Plant Characteristics Associated with } \\
\text { Average Wind Speed }\end{array}$} \\
\hline & $<=5.5$ & 7.4 & 8.0 & 8.4 & $>=10$ \\
\hline Specific Power $\left(W / m^{2}\right)^{*}$ & 129 & 152 & 159 & 164 & 199 \\
\hline Machine Rating (MW) & 5 & 5 & 5 & 5 & 5 \\
\hline Rotor Diameter (m) & 222 & 205 & 200 & 197 & 179 \\
\hline Hub Height (m) & 150 & 150 & 150 & 150 & 150 \\
\hline CapEx (\$/kW) & 1,295 & 1,213 & 1,200 & 1,183 & 1,099 \\
\hline OpEx (\$/kW/year) & 38 & 38 & 38 & 38 & 38 \\
\hline Capacity Factor & $42 \%$ & $56 \%$ & $59 \%$ & $61 \%$ & $65 \%$ \\
\hline $\begin{array}{l}\text { FCR (Post-PTC with A2e Risk-Reduction and } \\
\text { Extended Plant Life Capital Structure); } \\
\text { Nominal/Real WACC }=5.1 \% / 2.6 \%\end{array}$ & $5.2 \%$ & $5.2 \%$ & $5.2 \%$ & $5.2 \%$ & $5.2 \%$ \\
\hline $\begin{array}{l}\text { LCOE - Post-PTC w/A2e Risk-Reduction and } \\
\text { Extended Plant Life Capital Structure ( } \$ / M W h)\end{array}$ & 29 & 20 & 19 & 19 & 17 \\
\hline
\end{tabular}

${ }^{*}$ Assume specific power is linear across wind speed and range similar to 2-MW best in class available in 2016.

Table D-5. Projected 2030 Land-Based Wind Power Plant Characteristics for the Higher LCOE Range

\begin{tabular}{|c|c|c|c|c|c|}
\hline \multirow[b]{2}{*}{ Average Annual Wind Speed $(\mathrm{m} / \mathrm{s})$ at $80-\mathrm{m}$ Hub Height } & \multicolumn{5}{|c|}{$\begin{array}{c}\text { Wind Plant Characteristics Associated with } \\
\text { Average Wind Speed }\end{array}$} \\
\hline & $<=5.5$ & 7.4 & 8.0 & 8.4 & $>=10$ \\
\hline Specific Power $\left(\mathrm{W} / \mathrm{m}^{2}\right)^{*}$ & 182 & 219 & 227 & 237 & 307 \\
\hline Machine Rating (MW) & 3.25 & 3.25 & 3.25 & 3.25 & 3.25 \\
\hline Rotor Diameter (m) & 151 & 137 & 135 & 132 & 116 \\
\hline Hub Height (m) & 115 & 115 & 115 & 115 & 115 \\
\hline CapEx (\$/kW) & 1,505 & 1,423 & 1,410 & 1,393 & 1,309 \\
\hline OpEx (\$/kW/year) & 46 & 46 & 46 & 46 & 46 \\
\hline Capacity Factor & $30 \%$ & $44 \%$ & $48 \%$ & $50 \%$ & $53 \%$ \\
\hline $\begin{array}{l}\text { FCR (Post-PTC with IEA Wind Expert Survey Median } \\
\text { Capital Structure); } \\
\text { Nominal/Real WACC }=5.6 \% / 3.1 \%\end{array}$ & $6.4 \%$ & $6.4 \%$ & $6.4 \%$ & $6.4 \%$ & $6.4 \%$ \\
\hline $\begin{array}{l}\text { LCOE - Post-PTC w/A2e Risk Reduction and Extended } \\
\text { Plant Life Capital Structure (\$/MWh) }\end{array}$ & 53 & 35 & 32 & 31 & 28 \\
\hline
\end{tabular}

*Assume specific power varies with speed similarly to U.S. wind power plant installations in 2015. 


\section{Appendix E. Harnessing Immense Offshore and Distributed Wind Potential with Advanced Wind Technologies}

Thus far, this report has focused on utility-scale, land-based wind power plants that comprise the bulk of the U.S. wind energy fleet in the Wind Vision scenario (DOE 2015). However, A2e research advancements are also expected to benefit offshore wind technology that could be a significant portion of the overall electricity generation mix. Coastal regions tend to have relatively high population densities and electricity prices, as well as a lack of indigenous energy resources. These coastal regions are positioned to benefit greatly from cost-competitive offshore wind electricity generation (see e.g., Beiter et al. 2016; Marcy and Beiter 2016). In addition, for remote applications, distributed wind energy can also benefit from wind energy science improvements. Distributed wind energy could become a cost-competitive option behind the meter, leading to a significant role in the electricity generation mix. This section documents the innovations needed for these technology application areas and how A2e research can benefit these applications.

\section{Offshore Wind}

Offshore wind represents a substantial opportunity to enhance the diversity and security of the electricity supply for the nation (Gilman et al. 2016). Wind power plants in the ocean or Great Lakes region provide power generation close to load centers, minimizing the need for transmission, and have the ability to access a very high-capacity-factor resource. In some regions, such as the northeastern United States, ${ }^{14}$ the vast majority of wind energy is expected to be derived from offshore wind resources under the Wind Vision 2050 study scenario. Yet, offshore wind technology in the United States is less mature at this point and tends to have a higher cost than land-based wind applications. In Europe, recent winning tenders for offshore wind projects have dropped to cost levels that approach those of conventional technologies, as shown in Figure E-1 (Bloomberg New Energy Finance 2016).

Driving offshore wind costs down even further increases the chances for cost competitiveness in U.S. waters. These cost reductions are achievable with concerted A2e scientific efforts to advance offshore wind energy science along with structured innovation efforts by the offshore wind industry.

\footnotetext{
${ }^{14}$ The first commercial U.S. offshore wind project has commenced operation in 2016 off the coast of Block Island (Rhode Island).
} 


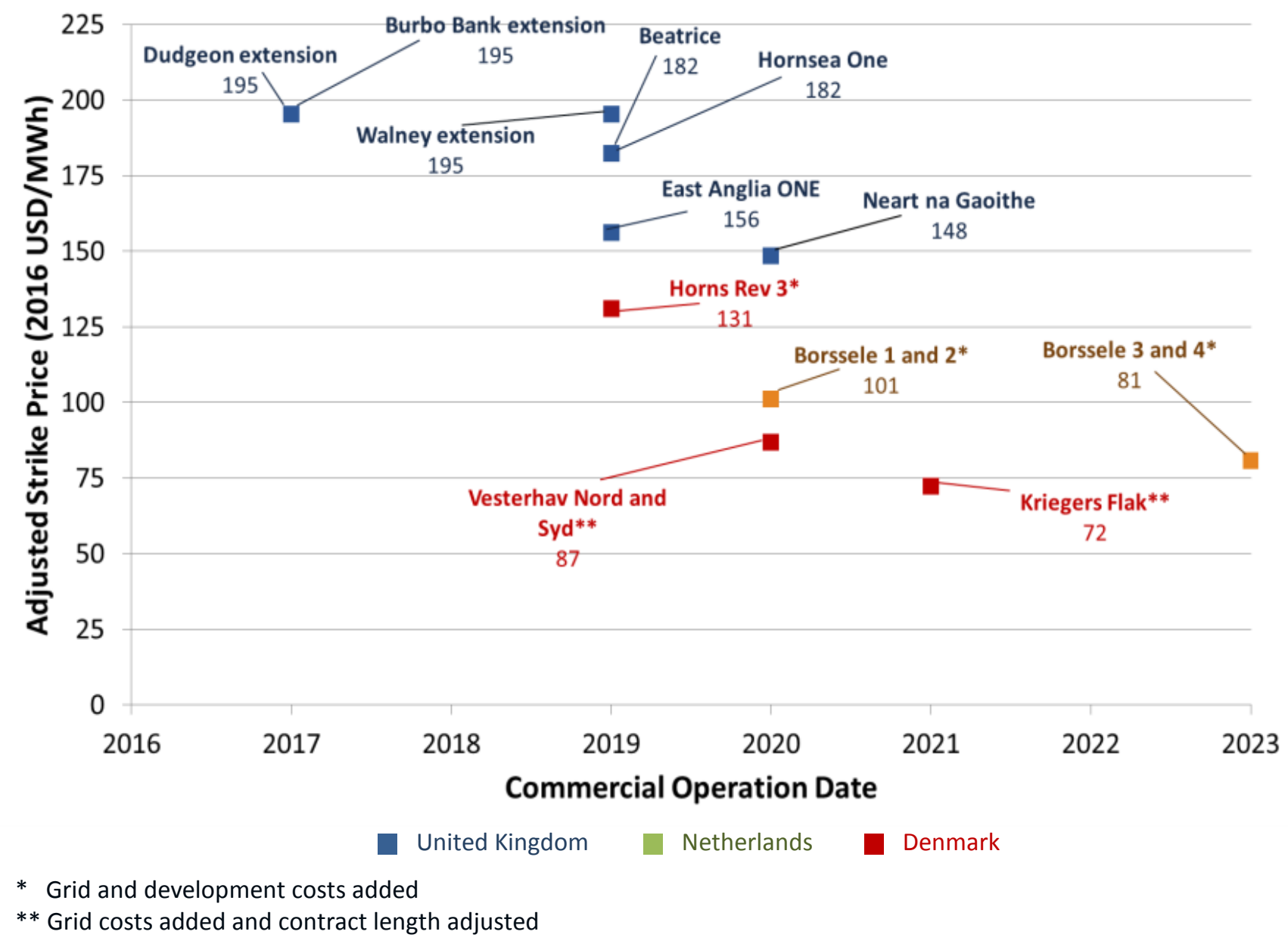

Figure E-1. Recent strike prices for offshore wind plants in European waters. Data derived from Garlick, Auckland, Zhang (2017) ${ }^{1}$

Industry technological advancements enabled by A2e R\&D to optimize wind power plant design, control, and operation described for land-based installations are also applicable to offshore, and in some cases, to an even greater extent. Offshore wind power plants place a high value on tightly spaced installations because of the high cost of underwater infrastructure. The design of the arrays of turbines, and their operation as an integrated unit, are at least as important as for any land-based installation. Predicting the production more accurately can help reduce the investment risk, which is arguably higher for offshore wind because of a more limited experience base.

Controlling the plant dynamically as a SMART wind power plant unit is expected to be required for large offshore plants of the future. Atmospheric conditions that are common offshore may also be those under which wind power plant control strategies are the most impactful. Because of the smooth nature of the sea relative to complex geography of the land, wakes created by upstream turbines will propagate further through the plant and increase the losses in the plant production as a whole. Further, because the offshore wind market is less mature, there is even greater opportunity to reduce the cost of electricity using innovative, full-power-plant technology. These innovations are being driven by the enhanced atmospheric flow simulation capabilities that are a key outcome of the A2e program. 


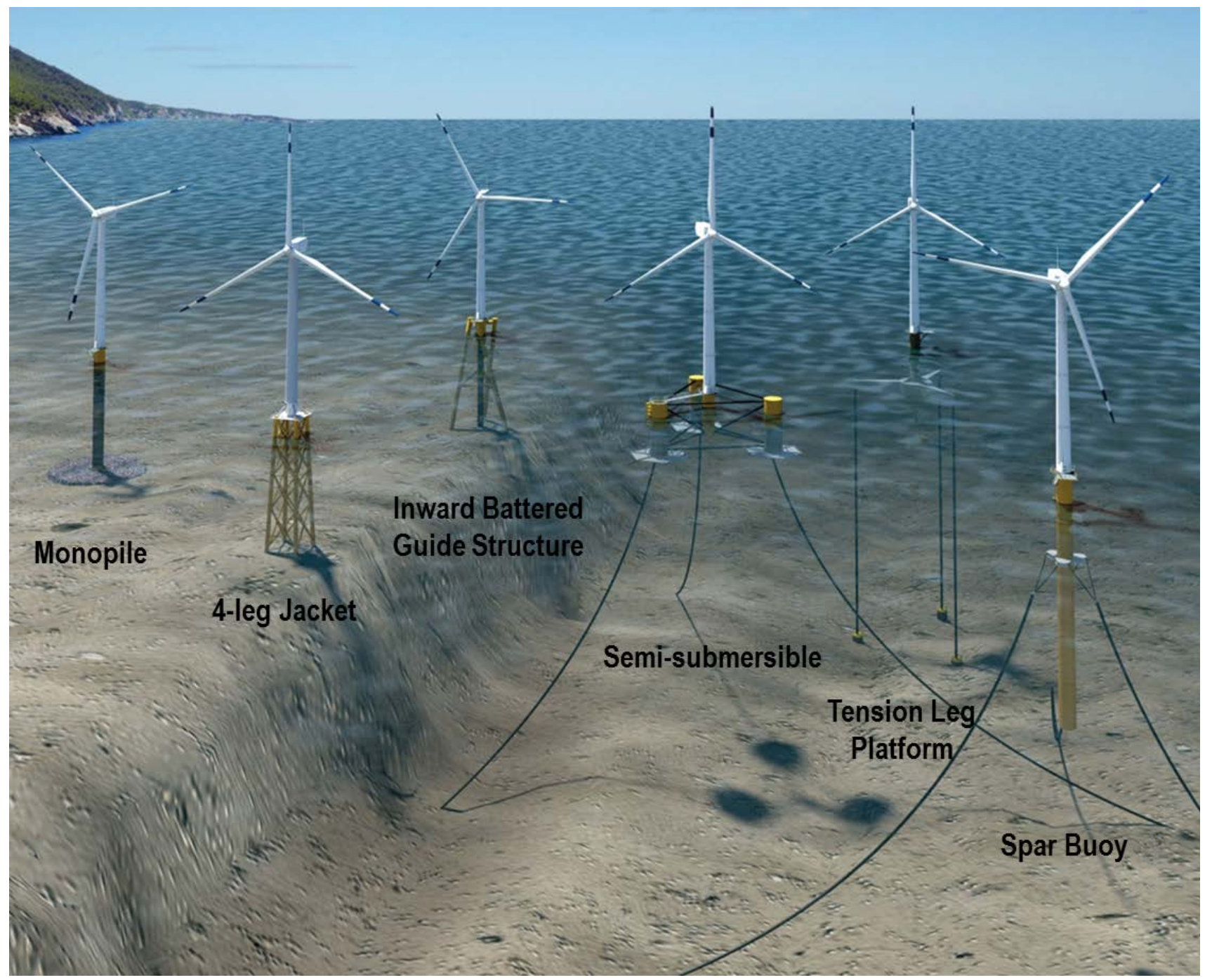

Figure E-2. Six different offshore wind substructure types. Offshore wind systems are enhancing foundation concepts to reduce the significant challenge of installation in deep water at a low cost. IIlustration by Josh Bauer, National Renewable Energy Laboratory

Innovative systems, especially floating foundations (as shown in Figure E-2), will require enhanced design tools that simulate offshore environments in combination with both turbinespecific and plantwide control. These innovations are extremely expensive to prototype because of their massive scale, which makes the ability to represent the combined soil, ocean, and atmospheric conditions in a simulation environment especially important. The A2e program's involvement in establishing those computational capabilities will be foundational to offshore wind success in challenging U.S. waters.

\section{Distributed Wind}

Distributed wind, as defined by the U.S. Department of Energy Wind Energy Technologies Office, has two basic characteristics: (1) proximity to end use where it is typically co-located with the energy user, and (2) a point of interconnection that is either behind the meter of the customer, on a distribution rather than transmission system, or off-grid entirely (DOE 2017). In addition to utility-scale, land-based wind and offshore wind, distributed wind applications also 
reflect a major opportunity to enhance the diversity and security of the nation's electricity supply. An initial estimate of the economic potential of distributed wind located in proximity to end users is 30-40 GW (with a market potential of 4-20 GW) (Lantz et al. 2016) by 2050.

The full spectrum of potential value associated with a SMART wind power plant is less meaningful for distributed applications employing only one or just a few turbines. However, the wide range of wind applications within the distributed wind market space offers opportunities. This range of applications includes small-scale wind farms installed as part of community wind developments (e.g., universities or for local municipal utilities), and onsite industrial clients will benefit from many of the SMART wind power plant concepts. The need to install such projects close to loads also means that they may be installed in areas with higher turbulence, increasing the benefits of advanced controls and atmospheric characterization.

Even in distributed wind applications that may have only one turbine at a given site, the insights gained from a more robust understanding of wind flow around wind turbines and landscape features generally will enable improved assessment of turbine performance and reliability and may provide other key information needed to improve the bankability of distributed wind projects. Smaller-scale wind turbines, less than $1 \mathrm{MW}$, that are deployed in distributed settings must also balance the demands of seeking high production in areas with less energetic winds, increased turbulence as a result of closer proximity to structures and trees, and the need for increased reliability in the absence of onsite maintenance staff. Even for smaller turbines, gains in each of these areas link directly back to improvements from understanding the fundamental physics of the wind resource and are necessary to enable the future cost reduction and innovations that could drive robust growth in distributed wind deployment going forward.

In the long term, distributed wind could mirror developments in the distributed solar market, with the added benefit of providing energy over a full 24-hour diurnal profile. This could provide additional grid support; for example, communication among individual turbines within a network of distributed turbines may provide potential advantages in grid management and individual turbine controls owing to the potential installation of turbines across a wide geographic area. The ability of turbines within this network to communicate directly with each other and then with larger wind farms could help track and forecast weather events, providing further regional benefits. Finally, improved turbine design tools and turbine standards, which are expected outcomes of the A2e effort, will improve the capabilities of the U.S. distributed wind manufacturing sector, providing the industry with the tools needed to improve the reliability of current and future wind turbine technologies, while lowering the overall LCOE. 